\title{
Using underwater video to evaluate the performance of the Fukui trap as a mitigation tool for the invasive European green crab (Carcinus maenas) in Newfoundland, Canada (\#20010)
}

First revision

\section{Editor guidance}

Please submit by 12 Dec 2017 for the benefit of the authors (and your \$200 publishing discount).

\section{Structure and Criteria}

Please read the 'Structure and Criteria' page for general guidance.

\section{Q Custom checks}

Make sure you include the custom checks shown below, in your review.

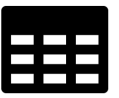

\section{Raw data check}

Review the raw data. Download from the materials page.

\section{Image check}

Check that figures and images have not been inappropriately manipulated.

Privacy reminder: If uploading an annotated PDF, remove identifiable information to remain anonymous.

Files

Download and review all files from the materials page.
1 Tracked changes manuscript(s)

1 Rebuttal letter(s)

8 Figure file(s)

5 Table file(s)

2 Raw data file(s)

2 Other file(s)

\section{(9) Custom checks}

\section{Field study}

Have you checked the authors field study permits?

Are the field study permits appropriate? 


\section{Structure your review}

The review form is divided into 5 sections.

Please consider these when composing your review:

\section{BASIC REPORTING}

2. EXPERIMENTAL DESIGN

3. VALIDITY OF THE FINDINGS

4. General comments

5. Confidential notes to the editor

You can also annotate this PDF and upload it as part of your review

When ready submit online.

\section{Editorial Criteria}

Use these criteria points to structure your review. The full detailed editorial criteria is on your guidance page.

\section{BASIC REPORTING}

Clear, unambiguous, professional English language used throughout.

Intro \& background to show context. Literature well referenced $\&$ relevant.

Structure conforms to Peer] standards, discipline norm, or improved for clarity.

Figures are relevant, high quality, well labelled $\&$ described.

Raw data supplied (see PeerJ policy).

\section{EXPERIMENTAL DESIGN}

Original primary research within Scope of the journal.

Research question well defined, relevant $\&$ meaningful. It is stated how the research fills an identified knowledge gap.

Rigorous investigation performed to a high technical \& ethical standard.

Methods described with sufficient detail \& information to replicate.

\section{VALIDITY OF THE FINDINGS}

Impact and novelty not assessed. Negative/inconclusive results accepted. Meaningful replication encouraged where rationale $\&$ benefit to literature is clearly stated.

Data is robust, statistically sound, $\&$ controlled.
Conclusions are well stated, linked to original research question $\&$ limited to supporting results.

Speculation is welcome, but should be identified as such. 


\section{Standout \\ reviewing tips}

The best reviewers use these techniques

Tip

\author{
Support criticisms with \\ evidence from the text or from \\ other sources
}

\section{Give specific suggestions on how to improve the manuscript}

\section{Comment on language and grammar issues}

\author{
Please provide constructive \\ criticism, and avoid personal \\ opinions
}

\section{Example}

Smith et al (J of Methodology, 2005, V3, pp 123) have shown that the analysis you use in Lines 241-250 is not the most appropriate for this situation. Please explain why you used this method.

Your introduction needs more detail. I suggest that you improve the description at lines 57- 86 to provide more justification for your study (specifically, you should expand upon the knowledge gap being filled).

The English language should be improved to ensure that an international audience can clearly understand your text. Some examples where the language could be improved include lines 23, 77, 121, 128 - the current phrasing makes comprehension difficult.

1. Your most important issue

2. The next most important item

3....

4. The least important points

I thank you for providing the raw data, however your supplemental files need more descriptive metadata identifiers to be useful to future readers. Although your results are compelling, the data analysis should be improved in the following ways: $A A, B B, C C$

I commend the authors for their extensive data set, compiled over many years of detailed fieldwork. In addition, the manuscript is clearly written in professional, unambiguous language. If there is a weakness, it is in the statistical analysis (as I have noted above) which should be improved upon before Acceptance.
Comment on strengths (as well as weaknesses) of the manuscript 


\section{Using underwater video to evaluate the performance of the Fukui trap as a mitigation tool for the invasive European green crab (Carcinus maenas) in Newfoundland, Canada}

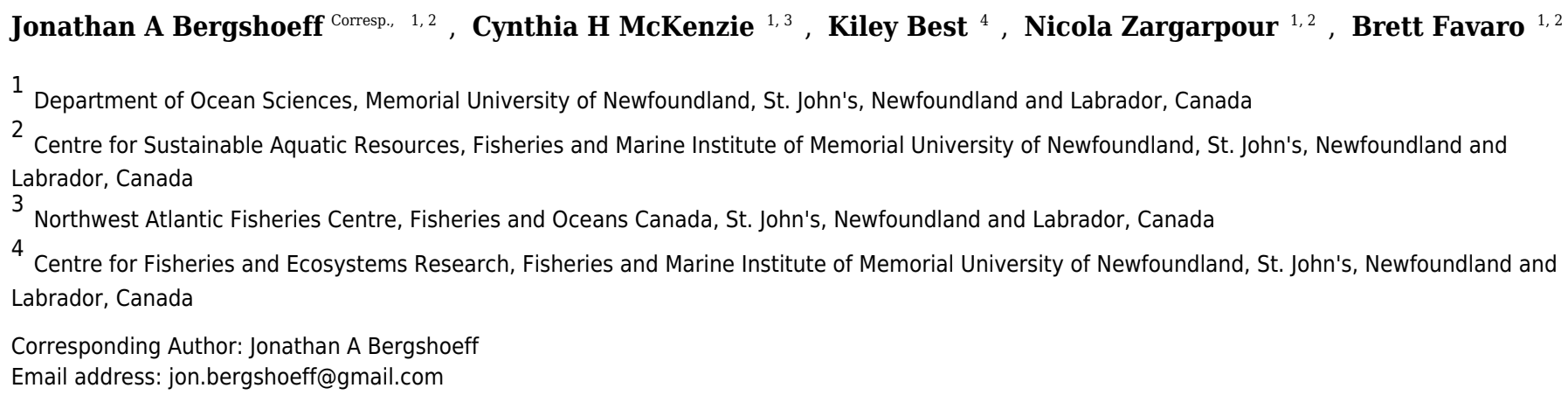

The European green crab (Carcinus maenas) is a destructive marine invader that was first discovered in Newfoundland waters in 2007 and has since become established in nearshore ecosystems on the south and west coast of the island. Targeted fishing programs aimed at removing green crabs from invaded Newfoundland ecosystems use Fukui traps, but the capture efficiency of these traps has not been previously assessed. We assessed Fukui traps using in situ observation with underwater video cameras as they actively fished for green crabs. From these videos, we recorded the number of green crabs that approached the trap, the outcome of each entry attempt (success or failure), and the number of exits from the trap. Across eight videos, we observed 1,226 green crab entry attempts, with only a $16 \%$ rate of success from these attempts. Based on these observations we believe there is scope to improve the performance of the Fukui trap through modifications in order to achieve a higher catch per unit effort (CPUE), maximizing trap usage for mitigation. Ultimately, a more efficient Fukui trap will help to control green crab populations in order to preserve the function and integrity of ecosystems invaded by the green crab. 
1 Using underwater video to evaluate the performance of the Fukui trap as a

2 mitigation tool for the invasive European green crab (Carcinus maenas) in

3 Newfoundland, Canada

4 Jonathan A. Bergshoeff ${ }^{1,2}$, Cynthia H. McKenzie ${ }^{2,4}$, Kiley Best ${ }^{3}$, Nicola Zargarpour ${ }^{1,2}$, Brett

5 Favaro $^{1,2}$

$6 \quad{ }^{1}$ Centre for Sustainable Aquatic Resources, Fisheries and Marine Institute of Memorial

7 University of Newfoundland, St. John's, NL, Canada

$8 \quad{ }^{2}$ Department of Ocean Sciences, Memorial University of Newfoundland, St. John's, NL, Canada

$9 \quad{ }^{3}$ Centre for Fisheries and Ecosystems Research, Fisheries and Marine Institute of Memorial

10 University of Newfoundland, St. John's, NL, Canada

$11{ }^{4}$ Northwest Atlantic Fisheries Centre, Fisheries and Oceans Canada, St. John's, NL, Canada

13 Corresponding Author:

14 Jonathan A. Bergshoeff

15 Email address: jon.bergshoeff@gmail.com 
ABSTRACT

The European green crab (Carcinus maenas) is a destructive marine invader that was first

22 discovered in Newfoundland waters in 2007 and has since become established in nearshore

23 ecosystems on the south and west coast of the island. Targeted fishing programs aimed at

24 removing green crabs from invaded Newfoundland ecosystems use Fukui traps, but the capture

25 efficiency of these traps has not been previously assessed. We assessed Fukui traps using in situ

26 observation with underwater video cameras as they actively fished for green crabs. From these

27 videos, we recorded the number of green crabs that approached the trap, the outcome of each

28 entry attempt (success or failure), and the number of exits from the trap. Across eight videos, we

29 observed 1,226 green crab entry attempts, with only a $16 \%$ rate of success from these attempts.

30 Based on these observations we believe there is scope to improve the performance of the Fukui

31 trap through modifications in order to achieve a higher catch per unit effort (CPUE), maximizing

32 trap usage for mitigation. Ultimately, a more efficient Fukui trap will help to control green crab

33 populations in order to preserve the function and integrity of ecosystems invaded by the green

34 crab. 


\section{Introduction}

The European green crab, Carcinus maenas (Linnaeus, 1758) is a crustacean species

native to European and North African coastlines (Williams, 1984). It has been ranked among 100 of the world's 'worst invasive alien species' by the International Union for Conservation of Nature (Lowe et al., 2000). In North America, current distributions of the European green crab (hereafter green crab) on the west coast range from California, USA (Cohen, Carlton \& Fountain, 1995; Yamada et al., 2008) up to British Columbia, Canada (Gillespie et al., 2007). On the east coast green crabs can be found from Virginia, USA (Williams, 1984) to Newfoundland, Canada (Blakeslee et al., 2010; McKenzie et al., 2011). Evidence suggests that green crab populations on the east coast are made up of both northern and southern genotypes that originated from two separate introduction events. First, the historical invasion of the northeastern United States in the early 1800's Dy green crabs originating from the southern UK (Say, 1817; Roman, 2006; Blakeslee et al., 2010). Second, anrintroduction into the Maritimes in the late 1980 's by a more cold-tolerant population from the northern limit of the green crab's range in Europe (Roman, 2006; Blakeslee et al., 2010; DFO, 2011a).

The green crab was first discovered in the nearshore waters of Newfoundland in 2007, and has since become established across the southern and western coasts of the island (DFO, 2011a). Genetic analysis of green crab populations indicate a mixed ancestry of both the southern and northern genotypes, with a close relationship to the more cold-tolerant, northern population (Blakeslee et al., 2010; DFO, 2011a). Recent findings show that green crab populations on the west coast of Newfoundland (i.e. St. George's Bay) are genetically different from those on the southeast coasts (i.e. Placentia Bay), which could manifest itself in different behaviours and invasion characteristics (Rossong et al., 2012; Jeffery et al., 2017). The invasion 
58 is concerning because green crabs destroy eelgrass beds (DFO, 2011a; Matheson et al., 2016), are voracious predators of bivalves (Ropes, 1968; Cohen, Carlton \& Fountain, 1995; Klassen \& Locke, 2007; Matheson \& McKenzie, 2014), and compete with native species and other crustaceans for food and habitat (Cohen, Carlton \& Fountain, 1995; Matheson \& Gagnon, 2012). The impact of green crabs on eelgrass beds is particularly threatening as invasive species are one of the multiple stressors contributing to a global trend in seagrass decline (Orth et al., 2006). Eelgrass serves as important habitat for commercial species such as cod, herring, and lobster. Therefore, green crab invasions pose both an ecological and economic threat (Joseph, Schmidt \& Gregory, 2013; Matheson et al., 2016).

The complete eradication of an invasive species in an aquatic environment is virtually impossible once the organism has become established, unless the invasion is in a confined area and addressed shortly after arrival (Bax et al., 2003; Lodge et al., 2006). In Newfoundland, the complete eradication of green crabs is no longer considered an option. Therefore, efforts are now focused on mitigation to suppress invasive populations to slow their spread and minimize their negative effects (DFO, 2011b). These mitigation studies have found that the direct removal of green crabs through focussed trapping is one effective control technique, and has become the current method of conducting targeted removals of green crabs on both the east and west coast of Canada (DFO, 2011a,b; Duncombe \& Therriault, 2017). Green crab removal efforts in Canada usually utilize Fukui traps (60 x 45 x $20 \mathrm{~cm}, 12 \mathrm{~mm}$ bar length square mesh, $45 \mathrm{~cm}$ expandable entry slit) which are practical for mitigation efforts as they are light-weight, collapsible, durable, and can be easily deployed from small boats or from shore.

Despite the widespread use of the Fukui trap for research, monitoring, and mitigation, there have been no formal investigations of the interactions between green crabs and the standard 
81 Fukui trap, and substantial knowledge gaps exist surrounding the trap's overall efficiency. In addition, it has been shown that green crab aggression and feeding behaviour can vary across sites, which may influence catch rates and the performance of the trap between areas (Rossong et al., 2012). The main objectives of this study were to evaluate the performance and efficiency of the Fukui trap in terms of its ability to catch green crabs, and to gain a better understanding of this capture process and how it may differ across sites in Newfoundland.

In this study, we used underwater video cameras to record footage of the traps as they actively fished for green crabs in situ across Newfoundland. Underwater video is the best way to understand the interactions between an animal and a piece of fishing gear, and is beneficial in determining the optimal design and use of this fishing gear (Favaro et al., 2012; Underwood, Winger \& Legge, 2012). There is a growing body of literature on the use of cameras to better understand various types of fishing gears, including traps (alternatively referred to as pots) (Jury et al., 2001; Barber \& Cobb, 2009; Bacheler et al., 2013; Favaro, Duff \& Côté, 2013; Meintzer, Walsh \& Favaro, 2017), trawls (Nguyen et al., 2014; Underwood et al., 2015), and hooks (He, 2003; Robbins et al., 2013). In the case of the Fukui trap, underwater video is an effective method to accurately assess the number of green crabs that approach the trap, the outcome of each attempt to enter the trap, and the likelihood that a green crab will remain inside the trap before it is retrieved.

Six steps have to be completed successfully for green crabs to be caught in a trap (Fig. 1) (Favaro, Duff \& Côté, 2014). First, they must be present in the area where the Fukui trap has been deployed. Second, they must be able to detect the presence of the trap, either visually or by detecting olfactory cues of the bait plume. Third, green crabs must approach the Fukui trap. Fourth, they must locate one of the entrances and make an entry attempt. Fifth, they must 
104 successfully complete that entry attempt in order to become captured. Sixth, they must remain in 105 the trap until the gear is hauled (i.e. they must not exit). The use of underwater video cameras in 106 this study enabled us to accurately evaluate steps three through six of the capture process 107 (number of approaches to the trap, proportion of successful entry attempts, number of exits) in 108 order to determine the effectiveness of the Fukui trap at catching green crabs. Furthermore, the 109 use of underwater video allowed us to identify barriers that were inhibiting the capture process. 110 This information will enable us to identify inefficiencies in the capture process that could be 111 addressed through modifications to the fishing gear, so that future removal programs can be 112 conducted more efficiently.

\section{Methods}

\section{1 - Camera apparatus and equipment}

116 We used custom-built camera housings with Sony HDR-AS20 Action Cameras capable of 117 recording 13-hour high-definition underwater videos (as described in Bergshoeff et al., 2017).

118 We mounted each camera system to a wooden frame built around a standard Fukui trap. Using a 119 large 114-165 mm diameter gear-clamp, the camera housing was centred above the trap, with the 120 camera pointing downward to provide a top-down view of the trap and surrounding area (Fig. 2).

121 The camera was positioned at a height of $53 \mathrm{~cm}$ above the top of the trap and $74 \mathrm{~cm}$ above the 122 ocean floor, creating a field-of-view (FOV) of approximately $81 \mathrm{~cm}$ by $150 \mathrm{~cm}$ when filming 123 underwater. The wide-angle lens of the camera made it possible to view the entire trap, in 124 addition to a buffer surrounding all edges of the trap $(45 \mathrm{~cm}$ to the left and right edge of the trap, 125 and $18 \mathrm{~cm}$ from the top and bottom edge). The wooden frame was weighted down with four 2.8 $126 \mathrm{~kg}$ cement bricks in order to make it negatively buoyant and to prevent shifting due to currents 
127 and wave action. Finally, the rope attaching the trap to the surface float was marked in half-metre 128 increments in order to determine the approximate depth of deployment.

An external lighting system was necessary for overnight trap deployments; therefore,

130 each camera apparatus was equipped with two Light and Motion (Marina, California, USA)

131 Gobe Plus flashlights with red LED light attachments (Gobe Focus Head). On low-power mode

132 these flashlights had sufficient battery life to illuminate the entire night cycle. Many crustaceans

133 are insensitive to wavelengths greater than $620 \mathrm{~nm}$; therefore, we used red lights with the goal of

134 minimizing the behavioural impacts that may accompany full-spectrum light (Nguyen et al., 135 2017).

\section{2 - Field methods}

We recorded underwater videos at six sites across Newfoundland during the summer of

1392015 and one site during the summer of 2016 (Fig. 3). We produced the map in Figure 3 using 140 the ggmap package (Kahle \& Wickham, 2013) in R (R Core Team, 2015). The sites were as

141 follows: 1. Fair Haven (FH), Placentia Bay (June 9-11, 2015 \& August 18-20, 2015) 2. Boat

142 Harbour (BH), Placentia Bay (June 23-26, 2015) 3. Little Harbour East (LHE), Fortune Bay

143 (June 22-23, 2015) 4. Little Port Harmon (PH), St. George’s Bay (July 7-10, 2015) 5. Penguin

144 Arm (PA), Bay of Islands (July 14-15, 2015) 6. Deer Arm (BB), Bonne Bay (July 11-14, 2015)

145 7. Fox Harbour (FX), Placentia Bay (June 30 - July 1, 2016). Each of these shallow, coastal sites

146 have known green crab populations, and consist of similar mixed mud, sand, and rock habitat.

147 The video data from June 2016 in Fox Harbour, NL were collected as part of a complementary

148 study that followed the same methodology for recording videos, and we therefore included the 149 results in our analysis. 
At each site we followed a set procedure for deploying the camera traps. Prior to each

151

152

153

154

155

156

157

158

159

160

161

162

163

164

165

166

167

168

169

170

171

172

deployment, the Fukui traps were baited with equal amounts of Atlantic herring (Clupea

harengus), the standard bait used by Fisheries and Oceans Canada (hereafter, DFO) for green

crab mitigation projects, in a perforated plastic bait container (Gillespie et al., 2007; DFO,

2011b). The herring was thawed and cut into pieces, with approximately half a fish placed into

each bait container. Once the traps were baited, the camera equipment was secured inside the

camera housing and mounted to the frame surrounding the Fukui trap. We used a wireless Sony

RM-LVR1 Live View Remote to ensure that the camera and FOV were oriented correctly and to initiate recording prior to each trap deployment.

We typically deployed the traps close to shore $(<50 \mathrm{~m})$ using a small Zodiac boat. When we placed the traps in the water, we made sure that the camera housing entered the water horizontally in order to prevent air bubbles from becoming trapped on the housing's acrylic viewport. We deployed each trap no less than $1 \mathrm{~m}$ below the low tide water depth to prevent the camera apparatus from breaching the surface with the changing tides. Each camera trap was paired with a Fukui trap without an attached camera to examine whether the camera itself affected catch rates. The two traps within each pair were placed approximately $10 \mathrm{~m}$ apart based on other studies involving the Fukui traps (Gillespie et al., 2007; Yamada et al., 2008; Curtis et al., 2015). In total, two camera traps and two non-camera traps were set at each deployment. Sampling location, global positioning system (GPS) coordinates, time of day, depth, and weather information were recorded for each deployment. Traps were either deployed early in the day and retrieved in the evening (termed 'daytime deployments'), or deployed before sunset and retrieved the next morning (termed 'overnight deployments'). We aimed for each trap to be deployed for $12 \mathrm{~h}$, but logistical factors such as weather and travel sometimes affected trap retrieval time 
173 adding variation to total soak time. These logistical factors also meant that some traps were not

174 deployed until the afternoon, and retrieved the following morning (termed 'mixed

175 deployments').

176 When the traps were retrieved the catch was sorted, counted, and sexed. All bycatch

177 species were visually identified to the lowest possible taxonomic level, recorded and released as

178 soon as possible. As per DFO recommendations, all captured green crabs were euthanized by

179 freezing and disposed of. Once the catch was processed, the camera equipment was reset, and the

180 traps were prepared for re-deployment. We re-baited the traps with fresh herring before each new

181 deployment.

182 The project was approved as a 'Category A' study by the Institutional Animal Care

183 Committee at Memorial University as it involved only invertebrates (project \# 15-02-BF), and all

184 field research was conducted under experimental licenses NL-3133-15 and NL-3271-16 issued

185 by DFO.

186 Throughout our manuscript, data description was done using the mean and standard

187 deviation (SD). When reporting a mean, we included the SD in parentheses. When reporting a

188 range, we included the mean and SD in parentheses.

189

\section{3 - Determining the effect of camera presence on catch}

We built two linear mixed-effects models using the nlme package (Pinhero et al., 2017)

192 in R (R Core Team, 2015) in order to test whether the presence of the camera had an effect on 193 green crab catch. We analyzed a subset of the green crab catch data which included only Fair

194 Haven, NL and Little Port Harmon, NL. All other sites were excluded from our subset due to 195 either zero green crab catch, or low mean catch rates (Table 1). We did not see any meaningful 
196 relationship between deployment duration and catch (Fig. 4A, 4B). However, the soak times

197 were not consistent between Fair Haven (range $=21.8-24.3 \mathrm{~h}$; mean $=22.9 \mathrm{~h}$; SD $=0.8$ ) and

198 Little Port Harmon (range $=7.4-14.1 \mathrm{~h}$, mean $=11.1 \mathrm{~h} ; \mathrm{SD}=2.8)($ Fig. 4C). To account for

199 this, we created a separate model for each location because the underlying effect of soak time on

200 catch was potentially unique to each site (Fig. 4D). These two models tested the fixed effects of

201 camera presence (i.e. camera present, camera absent) and duration on catch-per-deployment. We

202 did not include deployment type (i.e. daytime, overnight, mixed) in our final models as the term

203 was insignificant in the Little Port Harmon model, and lacked sufficient factor levels in the Fair

204 Haven model (mixed deployments only). Due to the paired nature of our design we designated

205 each camera and non-camera pair as a single deployment, which was included in each model as a

206 random effect. The residuals for both the Fair Haven and Little Port Harmon models met the

207 assumptions for homogeneity, normality, and independence.

208

209

210

2.4 - Video analysis

\subsection{1 - Video selection}

In order to determine which videos to analyze in-full, we first reviewed them according

212 to a selection key (Fig. S1). This process involved evaluating the level of green crab activity in

213 each video, as well as an assessment of the overall image quality. The activity level of each

214 video was determined by counting the approximate number of green crabs present in the field of

215 view (FOV) at 35-min intervals and calculating the overall mean across those intervals. The

216 average number of green crabs in the FOV corresponded to the following activity levels: $0=$

217 'none'; $0.1-5.0=$ 'low'; $5.1-10.0=$ 'medium'; 10.0 and above $=$ 'high'. If the activity level

218 was determined to be 'none' or 'low' the video was disqualified. Our assessment of video quality 
219 was based on visibility of the trap due to particulate matter and lighting conditions. If the lower 220 panel (i.e. the floor) of the Fukui trap was clearly visible, as well as the entire periphery of the 221 FOV, then the video quality was classified as 'good'. If the lower panel of the Fukui trap was 222 clearly visible, but the periphery of the FOV was poorly lit, then the video quality was classified as 'fair'. Finally, if the lower panel of the Fukui trap was not visible due to lighting or particulate matter, the video quality was classified as 'poor'. If the video quality was determined to be 'poor', the video was disqualified. Overall, in order to qualify for analysis each video required 'medium' or 'high' activity levels, as well as 'fair' or 'good' video quality.

\subsection{2 - Video analysis procedure}

We used a standardized procedure to evaluate the video obtained during the 2015 and 2016 field seasons. Video files were viewed using VLC Media Player 2.2.4 on a 27-inch (68.6 cm) 16:9 (widescreen) flat screen monitor. For night videos, we used the sepia colour setting in

232 VLC to reduce glare and eye-strain caused by the red lighting. Data were recorded in a 233 spreadsheet using Microsoft Excel 2013. The analysis procedure involved characterizing the 234 video by "events" (both qualitative and quantitative) and recording the time during the video at 235 which each event occurred.

236 We began analyzing the video as soon as the trap settled on the ocean floor after 237 deployment. The FOV was divided into four sections in a clockwise manner $($ top $=1$, right $=2$, 238 bottom $=3$, left $=4$ ). Every time an animal entered the FOV, we recorded the direction of 239 approach (e.g. APP1, APP2), the species (e.g. GC for green crab, RC for rock crab), and the time 240 as indicated by the VLC time counter. A rough estimate of size was made for each species

241 (small, medium, or large); however, limited emphasis was placed on this information due to the 
242 potential for biases and size distortion depending on the distance of a green crab from the 243 camera.

We recorded each attempt to enter the trap, along with the time taken to complete or fail the attempt. For green crabs, an attempt was defined as when the entire body of the crab was

246 inside the entry tunnel of either entrance 1 or entrance 2 (Fig. 5). The time for each attempt was 247 recorded until the entry was either successful (i.e. a green crab fully entered the trap) or failed

248 (i.e. a green crab fully left the entrance tunnel). If an entry attempt failed, the predominant reason 249 for failure was noted according to four common, reoccurring situations: 1) Agonism (AGON): 250 some form of intraspecific or interspecific agonistic behaviour deterred or prevented the green 251 crab from entering the trap, 2) Partial entry (PE): the green crab entered the entrance tunnel, but 252 turned around and exited before contacting the trap entry slit, 3) Full entry (FE): the green crab 253 fully entered the entrance tunnel and contacted the trap entry slit, but subsequently turned around 254 and exited, or 4) Difficulty completing entry (DCE): the green crab fully entered the entrance 255 tunnel, but was unable to get through the trap entry slit in order to successfully complete the 256 entry, and subsequently turned around and exited. Additionally, if a green crab was able to 257 escape the trap after it had successfully entered, this was recorded as an exit.

If a notable behaviour occurred that was not part of our core observation framework (e.g. 259 predation) we recorded the time and context of the event. We focused on behavioural 260 interactions outside of the trap instead of green crabs already inside the trap, which could be seen 261 as an artificial environment influencing behaviour. 
Recently, it has been shown that genetically different green crab populations exist within

265 Newfoundland which could influence behaviour and catchability (Rossong et al., 2012; Jeffery et

266 al., 2017). We compared video analysis results between St. George's Bay (i.e. Little Port

267 Harmon) on the west coast of Newfoundland, and Placentia Bay (i.e. Fair Haven and Fox

268 Harbour) on the southeast coast in order to examine regional differences in the performance of

269 the Fukui trap. When comparing these regional differences, we focused on parameters related

270 directly to the interactions of green crabs with the Fukui trap. This allowed us to evaluate

271 whether variations in regional green crab behaviour had an impact on Fukui trap performance.

272 The two parameters we examined were the elapsed time for successful and failed entry attempts,

273 and the frequency of these attempts.

274 We used a generalized linear mixed model (GLMM) to test whether there was an

275 interaction between the elapsed time for successful or failed green crab entry attempts, and

276 region. To build our model we used the lme4 package (Bates et al., 2017) in R (R Core Team,

277 2015). The distribution of elapsed entry attempt time was best explained by a negative binomial

278 distribution. The fixed covariates in our model were outcome (categorical with two levels:

279 success, failure) and region (categorical with two levels: west, southeast). We included video ID

280 as a random effect to account for dependency among observations from the same video. We

281 verified the assumptions of our model by plotting residuals versus fitted values, and testing for

282 overdispersion.

283 We assessed whether there was an association between the frequency of entry attempt

284 outcomes (i.e. successful entry, failed entry) and region (i.e. west, southeast) using a chi-squared

285 test. We set the level of statistical significance for rejecting the null hypothesis at $\mathrm{p}<0.05$. 
287 3. Results

$288 \quad 3.1$ - Field deployments

289 During the 2015 field season, a total of 39 camera traps and 39 traps without cameras 290 were deployed (total $n=78$ ) across the six field sites. Trap deployment times ranged from 2.7 to

$29124.4 \mathrm{~h}($ mean $=14.2 \mathrm{~h} ; \mathrm{SD}=6.1)$. We collected 37 videos in total (Table S1). Two of the 39

292 videos failed due to partial flooding of the camera housing. Recording duration of videos ranged 293 from 2.7 to $13.0 \mathrm{~h}($ mean $=11.2 \mathrm{~h} ; \mathrm{SD}=2.7)$. The inconsistency in deployment durations can be 294 attributed to a combination of logistical challenges getting to-and-from the site and inclement 295 weather preventing retrieval of the gear.

Both the fishing effort and the number of green crabs caught per trap varied across the six 297 study sites visited in 2015, with all but two of the sites (Fair Haven and Little Port Harmon) 298 exhibiting a mean catch of less than 10 green crabs per deployment (Table 1). Generally, bycatch 299 using the Fukui trap was minimal. The most common occurrence of bycatch was rock crab 300 (Cancer irroratus) in Boat Harbour and Bonne Bay (Table 2).

\section{2 - Camera effects}

We found the presence of the camera had no significant impact on catch at both Fair

304 Haven $(\beta 1=19.409$, S.E. $=46.797, \mathrm{t}=0.415, \mathrm{p}=0.693)$ and Little Port Harmon $(\beta 1=-15.951$,

305 S.E. $=16.970, \mathrm{t}=-1.268, \mathrm{p}=0.273$ ) based on our subset of catch data from these two locations.

306 The effect size, $\beta 1$, can be interpreted as an increase of 19 crabs per trap when a camera is

307 present at Fair Haven, and a decrease in 16 crabs per trap when the camera is present at Little

308 Port Harmon, both relative to non-camera traps. Camera traps fished in Fair Haven $(\mathrm{n}=8)$ caught between 10 and 299 green crabs (mean = 140.9 crabs; SD =99.6), and non-camera traps 
310 fished in Fair Haven $(\mathrm{n}=8)$ caught between 18 and 232 green crabs (mean = 122.6 crabs; $\mathrm{SD}=$

311 80.9). Camera traps fished in Little Port Harmon $(n=6)$ caught between 3 and 74 green crabs

$312($ mean $=26.3$ crabs; $\mathrm{SD}=26.3)$, and non-camera traps $(\mathrm{n}=6)$ fished in Little Port Harmon

313 caught between 0 and 102 green crabs (mean $=42.5$ crabs; $\mathrm{SD}=34.4)$.

\section{3 - Video analysis}

Using the video selection key (Fig. S1), we determined that 8 of the 37 collected videos

317 were suitable for complete analysis (Table S2). The majority of videos that were rejected from

318 the analysis process showed no or 'low' green crab activity. Overall, videos were clear and well

319 illuminated. However, videos collected at night under red illumination were dim around the

320 periphery of the FOV (Fig. 2). Additionally, videos collected in Fair Haven in late-August, 2015

321 were disqualified due to 'poor' quality caused by excessive turbidity and suspended particulate

322 material in the shallow bay in which we were trapping.

Results from the eight videos that were analyzed can be examined in Table 3 . The

324 variability among videos, and the range of green crab activity levels across each site are

325 illustrated in Figure 6. In total, we observed 2,373 green crab approaches to the trap over the

326 course of eight videos $(73.0 \mathrm{~h})$, and 351 by other species (Fig. 6A). During these videos, green

327 crabs comprised $86.0 \%(\mathrm{SD}=10.3)$ of all approaches to the trap, and it took $3.5 \mathrm{~min}(\mathrm{SD}=3.4)$

328 on average for the first green crab to approach the trap (range: $0.9-11.1 \mathrm{~min}$ ). We observed an

329 average of 35.7 green crab approaches per hour $(\mathrm{SD}=18.2)$ across all eight videos. Only $8.1 \%$

$330(\mathrm{SD}=5.2)$ of the 2,373 green crab approaches resulted in a successful entry into the Fukui trap.

331 No green crab exits were observed. 
We observed a total of 1,226 green crabs make attempts to enter the Fukui trap across all

333 sites (Fig. 6B), as well as 30 attempts by other species. On average, there were 18.0 entry

334 attempts per hour $(\mathrm{SD}=8.9)$, and $52.5 \%(\mathrm{SD}=10.9)$ of the green crabs that approached the trap

335 made entry attempts. In total, 181 green crabs made successful entry attempts (Fig. 6C). The

336 success rate for each video ranged from $0.9-32.5 \%$, with a mean of $16.0 \%(\mathrm{SD}=11.4)$. On

337 average, it took a green crab $140.3 \mathrm{~s}(\mathrm{SD}=147.8)$ to successfully enter the Fukui trap during an

338 entry attempt (range: $8-837 \mathrm{~s})$, while it took an average of $126.1 \mathrm{~s}(\mathrm{SD}=200.2)$ before a green

339 crab would fail an entry attempt (range: $3-2789$ s).

We observed 1,045 failed entry attempts in total. For each of the eight videos, the average

341 proportion of failed entry attempts was $84.0 \%(\mathrm{SD}=11.4)$. This proportion can be further

342 broken down according to the four most common reasons for failure (Fig. 7).

First, $4.0 \%(\mathrm{SD}=2.4)$ of all entry attempts failed due to some sort of agonistic behaviour

344 (AGON; $\mathrm{n}=51)$ preventing the green crab from entering the trap. If two green crabs were

345 making a simultaneous entry attempt, agonistic behaviour between them would often cause

346 either crab to abandon the entry attempt. We also observed crabs already inside of the entry

347 tunnel deterring other crabs from entering. This agonistic behaviour was not limited to crabs

348 outside of the trap; green crabs that were already successfully captured would occasionally

349 attempt to deter other crabs from entering the trap.

Second, $20.0 \%(\mathrm{SD}=12.2)$ of all entry attempts failed because the green crab entered the

351 entry tunnel, but only made a partial entry $(\mathrm{PE} ; \mathrm{n}=209)$ before exiting. There was often no

352 obvious behaviour driving partial entry attempts.

Third, $15.5 \%(\mathrm{SD}=7.4)$ of all entry attempts failed after the green crab fully entered the 
355 green crabs moved further inside the wedge-shape entry tunnel towards the entry slit, their 356 movement would become more restricted. Occasionally, the pereopod of a green crab would 357 hook the mesh $(1 \mathrm{~cm} \times 1 \mathrm{~cm})$ on the top or side panel of the entrance tunnel, causing the crab to 358 become redirected outside of the trap, instead of further inside.

Finally, $44.5 \%(\mathrm{SD}=14.4)$ of all entry attempts failed because the green crab had

360 difficulty getting through the trap entry slit in order to complete the entry (DCE; $n=570)$. The

361 amount of time spent by a green crab attempting to pass through the trap entry slit ranged from

36219 to $2,789 \mathrm{~s}($ mean $=194.5 \mathrm{~s} ; \mathrm{SD}=249.3)$. The sharp pereopods of green crabs would often 363 become entangled or caught in the mesh of the Fukui trap, inhibiting successful entry. Similarly, 364 the five anterolateral spines on either side of the green crabs' eyes would often catch on the mesh 365 of the entry slit during entry attempts. Furthermore, even without getting caught in the mesh of 366 the trap, the entry slit was often too tight for the crabs to easily slip through, causing them to 367 become stuck or entangled, and ultimately fail the entry attempt. If a crab was able to reach one 368 of its pereopods or chelipeds through the trap entry slit, there was often nothing to grab hold of 369 in order to pull itself through the tight-fitting entry slit, resulting in a failed entry attempt. Based on the 181 successful entry attempts, we observed several scenarios that assisted 371 green crabs in making a successful entry. If a crab approached the entrance tunnel at a fast pace, 372 it was often able to use this momentum to push through the restrictive trap entry slit with 373 minimal effort. Similarly, if a green crab approached the entry slit backwards, this would prevent 374 the forward-facing anterolateral spines of the carapace from becoming caught in the mesh. This 375 would allow green crabs to enter the trap more easily. In other situations, crabs would struggle 376 for sustained periods of time to pass through the trap entry slit, with some eventually achieving 
377 success. We also observed crabs using the bait container hanging in the centre of the trap to

378 assist in pulling themselves through the entry slit.

3.4 - Regional performance of the Fukui trap

The performance of the Fukui trap remained consistent across Newfoundland, regardless

of region (i.e. Fox Harbour and Fair Haven in southeastern Newfoundland, Little Port Harmon in western Newfoundland). We found there was no significant difference in elapsed entry attempt time between regions $(\beta 1=0.231, \mathrm{~S} . \mathrm{E} .=0.260, \mathrm{t}=0.889, \mathrm{p}=0.374)$, and we found no significant interaction between entry attempt outcome and region $(\beta 1=0.046$, S.E. $=0.159, \mathrm{t}=$ $0.287, p=0.774)$. From our video data, the average elapsed time for successful entry attempts in the west was $163.7 \mathrm{~s}(\mathrm{SD}=169.5)$, and $120.5 \mathrm{~s}(\mathrm{SD}=124.1)$ in the southeast. The average elapsed time for failed entry attempts in the west was $129.8 \mathrm{~s}(\mathrm{SD}=195.4)$, and $122.5 \mathrm{~s}(\mathrm{SD}=$ 204.8) in the southeast. Through our chi-squared test, we failed to reject the null hypothesis that there was no association between the frequency of entry attempt outcomes and region $\left(\chi^{2}=\right.$ $0.558, \mathrm{df}=1, \mathrm{p}=0.455)$. Based on all entry attempts within each region, the proportion of successful entry attempts was $14 \%$ in the west, and $16 \%$ in the southeast.

\section{Discussion}

\section{1 - Video quality}

In this study, we found underwater video to be an effective means of evaluating the Fukui

397 trap as it actively fishes for invasive green crabs in situ, providing information that could not be

398 inferred from catch data alone. However, there are inherent challenges associated with the 399 collection of data from video recordings. 
First, the illumination during nighttime deployments was dim around the periphery of the

401 FOV and the use of red lights had an impact on image quality due to high absorption of this

402 frequency in water (Williams et al., 2014). Therefore, the number of approaches recorded during

403 these deployments may have been less accurate than daytime deployments. This is a common

404 issue when recording video in low-light environments (Underwood, Winger \& Legge, 2012;

405 Favaro, Duff \& Côté, 2014). Both entry tunnels and the entry slits were clearly illuminated

406 during nighttime deployments. Therefore, the accuracy of entry attempt data remained consistent

407 across all deployments. Second, we were limited to videos collected in June and July due to poor

408 visibility caused by increased water temperature in mid-August. The videos collected in Fair

409 Haven in August 2015 had to be disqualified due to excessive turbidity and suspended particulate

410 material. Finally, as green crabs accumulated inside the Fukui trap, it became more difficult to

411 track individual crabs as they made entry attempts. As the density inside the trap increased, our

412 line-of-sight was often obstructed by green crabs already inside the trap. This may have had an

413 effect on the number of entry attempts recorded in videos with high green crab densities, which

414 could have ultimately influenced our calculations of entry attempt proportions.

\section{2 - Evaluation of the six-step capture process}

417 Through our video analysis, we have gained considerable insight into the performance of 418 the standard Fukui trap as a tool for green crab mitigation, as well as the behaviour of the green 419 crab in relation to the trap itself, other species, and other green crab. These findings can be 420 summarized using the framework of the six-step capture process (Fig. 1). 
The number of green crabs present in the areas where we deployed Fukui traps varied.

424 Effective trapping requires that green crabs be present in sufficient numbers within the area

425 being fished. Despite anecdotal evidence of established green crab populations at all sites

426 sampled in 2015, most of our green crab catch was limited to either Fair Haven and Little Port

427 Harmon (Table 1). We hypothesize that the low catch rates at the other locations could be

428 attributed to environmental factors. Newfoundland experienced a prolonged winter in $2014-$

4292015 with above normal ice extent, followed by a late spring warming (DFO, 2016). It has been

430 shown that unusually low winter temperatures can result in mass mortality of adult green crabs,

431 and poor recruitment (Crisp, 1964; Welch, 1968; Berrill, 1982; Beukema, 1991). These low

432 temperatures could have had an impact on green crab populations, producing less catch in certain

433 areas than was seen in previous years (Welch, 1968; Yamada \& Kosro, 2010).

When deploying the camera apparatus, we had to ensure that the camera would not

breach the water's surface with the changing tides. To account for this, we deployed the cameras approximately $1 \mathrm{~m}$ below low tide depth. Green crabs are most commonly found in depths

437 ranging from high tide levels to $5-6 \mathrm{~m}$, and have been reported at depths of up to $60 \mathrm{~m}$

438 (Crothers J. H., 1968; Klassen \& Locke, 2007). Despite the minimum depth limitation dictated

439 by the height of the camera above the Fukui trap, we are confident that the placement of our

440 traps was sufficient to catch green crabs if they were present at each trapping locatinn.

442 green crabs were present (Table 2). This suggests that the Fukui trap has a minimal impact on

443 native species, and is an appropriate trap for targeting green crabs in areas where other species

444 are present. Presumed predation by green crabs causing bycatch mortality was rare, and limited

445 to soft-bodied species such as winter flounder (Pseudopleuronectes americanus), cunner 
446 (Tautogolabrus adspersus), and sculpin (Myoxocephalus sp.) in Fukui traps containing large 447 quantities of green crabs. We saw no mortality of rock crabs (Cancer irroratus) or American eel 448 (Anguilla rostrata), and all living bycatch present in the Fukui trap upon retrieval was released 449 alive.

Step 2 - Green crabs must detect the trap

Green crabs primarily use chemoreception to locate a food source (Shelton \& Mackie, 1971). It did not take long for green crabs to locate and approach our baited Fukui traps after they settled on the seafloor. On average, the first green crab would approach the Fukui trap within four min. Therefore, if green crabs were present in the area where the trap was deployed, then the olfactory cues from the herring functioned as effective bait. experiments on crustaceans have demonstrated that aligning a trap's entrances with the current (Miller, 1978; Vazquez Archdale et al., 2003). For this reason, when targeting green crabs with the Fukui trap it may benefit catchability to align the entrance tunnels with the water direction, so that crabs can follow the bait's odour trail directly into the trap.

Step 3 - Green crabs must approach the trap

We observed a range of different behaviours associated with green crabs approaching the 466 Fukui trap. Some green crabs would make an entry attempt right away, entering the camera's 467 FOV and proceeding directly to the entrance tunnel. In other instances, green crabs would move 468 around the trap for long periods of time before discovering the entrance tunnel, or beginning an 
469 entry attempt. We frequently observed agonistic behaviour on and around the Fukui trap, 470 especially once green crabs began to accumulate in the area. Green crabs would often cluster on 471 top of the trap, situating themselves above the bait container (hanging inside the centre of the 472 trap) as if they were guarding a food source, a behaviour that has been noted with Dungeness 473 crab (Metacarcinus magister) (Barber \& Cobb, 2009). This behaviour would result in 474 confrontations between green crabs as they fought to either defend their position, or to displace 475 the green crab guarding the bait. It was common to witness one green crab pursuing another 476 around the trap, or to observe one crab grasping and immobilizing another. Size did not appear 477 related to which green crab was the aggressor. Green crabs not only exhibited intraspecific 478 agonistic behaviours, but often engaged with other species near the trap. It was not uncommon 479 for green crabs to display aggressive behaviour towards a larger fish species, such as winter 480 flounder.

Because we could not individually identify crabs as they entered and re-entered the FOV, 482 the number of approaches by green crabs to the Fukui trap does not represent the absolute 483 number of individual crabs that approached the trap. This is a common challenge associated in 484 situ camera studies (Favaro, Duff \& Côté, 2014). Despite this caveat, every entry attempt we observed can be considered a unique event, regardless of whether a green crab approached multiple times. If a target species repeatedly approaches a piece of fishing gear, yet fails to be captured, this suggests a fundamental problem with the fishing gear itself that must be addressed.

488 Furthermore, Miller (1978) demonstrated that unless a trap is efficient at capturing crabs shortly 489 after they approach a trap, they will begin to accumulate around the trap. This will increase the 490 frequency of agonistic interactions, causing many crabs to flee from the trap, reducing the 
491 capture efficiency. Therefore, for a trap to maximize efficiency, it must successfully capture a 492 target species shortly after it approaches.

493

Step 4-Green crabs must make an entry attempt

A total of 1,226 green crabs made entry attempts, of which the majority were unsuccessful $(n=1,045)$. We repeatedly observed four scenarios that resulted in failed entry attempts (i.e. AGON, PE, FE, DCE). These reoccurring failure scenarios occurred across all eight videos, demonstrating that both green crab behaviour, and Fukui trap performance issues remained consistent, regardless of location.

The least common reason for failed entry attempts was intraspecific and interspecific agonistic behaviour, which deterred or prevented green crabs from entering the Fukui trap. Aggressive behaviour is common in invasive species, allowing them to dominate over native species (Rehage \& Sih, 2004; Pintor et al., 2008; Weis, 2010). The green crab is no exception, and is known for exhibiting both intraspecific and interspecific agonistic behaviour (Rossong et al., 2006; Klassen \& Locke, 2007; Souza et al., 2011). This agonistic behaviour between green crabs has been shown to deter entry into baited traps (Crothers J. H., 1968; Gillespie et al., 2015). Similar behaviour has been documented in red rock crab (Cancer productus), Dungeness crab (Metacarcinus magister), and American lobster (Homarus americanus) where they have been observed guarding the entrances to traps, or using their bodies to prevent other individuals from entering the trap (Miller, 1978; Jury et al., 2001; Barber \& Cobb, 2009). We also observed this behaviour; however, these events only comprised $4 \%$ of all failed attempts, suggesting that it has a minimal impact on overall catchability. 
Partial and full entry attempts occurred when green crabs gained access to the entrance

514 tunnels, but did not make an active effort to pass through the trap entry slits. There was little

515 empirical evidence to explain these attempts beyond physical interactions between green crabs

516 and the Fukui trap. The pereopods of green crabs could easily pass through the mesh of the Fukui

517 trap, which would often cause them to become entangled or reoriented during entry attempts.

518 Furthermore, the entry tunnels of a Fukui trap narrow towards the entrance slit. This limited the

519 mobility of green crabs, and increased the likelihood that their pereopods would become

520 entangled as they advanced further inside the entrance tunnel. This influenced the direction and

521 orientation of the crab, and made it less likely that they would discover the entry slit in order to

522 gain access to the inside of the trap.

The most common failure scenario occurred when a green crab had difficulty completing

524 the entry attempt. This was characterized by the green crabs experiencing varying degrees of

525 difficulty passing through the entry slit of the trap, and subsequently abandoning the attempt.

526 The Fukui trap is designed so that a crab must force themselves through the entry slit, which

527 remains tightly closed in its default position. However, even the most determined green crabs

528 were often unable to enter the Fukui trap through these entry slits. A combination of mesh size

529 and the restrictive opening of the trap entry slit made successful entries difficult. These same

530 issues have been documented in a similar study with traps meant to target the Japanese rock crab

531 (Charybdis japonica) (Vazquez Archdale et al., 2003). In this study, Archdale et al. observed

532 crabs becoming entangled in the trap's netting material by their chelipeds and the spines on their

533 carapace. They observed that forward-facing entry attempts would frequently result in

534 entanglement, and difficulty in entering the trap. Furthermore, they observed that the trap's tight,

535 narrow entry slits prevented crabs from squeezing in, forcing them to abandon entry attempts. 
536 For green crabs attempting to enter the Fukui trap, the predominance of DCE events suggests

537 that the low catch rates are largely influenced by issues with the trap design itself, and not the

538 behaviour of green crabs.

Step 5 - Green crabs must successfully enter the trap

Across all videos, we witnessed at total of 181 green crabs successfully enter the Fukui trap, suggesting that the capture efficiency of the trap is low. Successful green crabs were perseverant, often struggling for long periods of time before maneuvering themselves through the restrictive trap entry slit. Certain entry strategies appeared to assist green crabs in successfully entering the Fukui trap, and body orientation was an important factor in facilitating successful entries. Most successful entries occurred when green crabs approached the entry slit sideways or backwards. In doing so, they were less prone to becoming entangled in the mesh as they pushed their way into the trap. These same entry strategies have been documented in Japanese rock crabs attempting to enter baited traps (Archdale, Kariyazono \& Añasco, 2006).

The force required to gain access to the Fukui trap would also make it challenging for green crabs to successfully enter the trap. Surprisingly, the bait container located in the centre of the trap would occasionally assist green crabs in making successful entry attempts. The tension

553 of the trap entry slit made it difficult for green crabs to push themselves through; however, if 554 they were able to make it partially inside the trap, grasping the bait container would often allow 555 them to pull themselves the rest of the way. This suggests that Fukui trap design would benefit 556 from a proprietary mechanism to assist green crabs in pulling themselves into the trap. There was great variability in success rates between videos, ranging from only $1 \%$ up to $33 \%$ (Table 3). When compared to similar studies of baited traps, the proportion of successful 
559 entry attempts into the Fukui trap is low. For example, traps used to capture Atlantic cod (Gadus morhua) and spot prawns (Pandalus platyceros) have successful entry attempt proportions of

$56122 \%$ and 46\%, respectively (Favaro, Duff \& Côté, 2014; Meintzer, Walsh \& Favaro, 2017). number of approaches was positively correlated with entry attempts, demonstrating that if there

564 were many approaches to the trap, there were generally many entry attempts (Fig. 6A and 6B).

565 The large number of attempts seen in Figure 6B indicates that green crabs were actively trying to 566 enter the Fukui trap. However, Figure 6C shows that this does not necessarily reflect how many 567 green crabs were actually captured.

Figure $6 \mathrm{C}$ demonstrates that catch is not an accurate representation of entry attempt effort, as the success rate varied widely. Certain videos (e.g. PH5) had many green crab entry attempts, resulting in comparatively high catch. However, some videos (e.g. FH3, PH1) had many approaches and attempts, yet caught very few crabs. We hypothesize that the varying success rates may have been due to the condition of the specific Fukui trap used. For example, if the metal frame of the trap was distorted in such a way that the tension of the entry slit was altered, this could affect how well a green crab is able to enter the trap. Alternatively, if the mesh of the trap is worn or sagging, this could promote successful entries by making the entry slit less restrictive. Although we did not record the condition of the Fukui traps used in our study, future experiments should test the performance of specific traps as a factor that could influence catch.

578 This hypothesis emphasizes the importance of regularly inspecting the condition of the Fukui 579 trap in order to promote successful entry attempts. 
582 crabs in the vicinity of the trap at the time of deployment. Over the course of a deployment, 583 many green crabs may attempt to enter a trap. However, as we have shown in this study, this 584 effort is not necessarily reflected in the number of crabs that are captured. This suggests that 585 final catch could produce a biased perception of low green crab abundance in the area being 586 fished. Other studies of crustacean catchability have demonstrated that traps can lead to biased 587 estimates of CPUE and abundance (Murray \& Seed, 2010; Kersey Sturdivant \& Clark, 2011; 588 Watson \& Jury, 2013). For green crabs, local abundance is often estimated by catch rate 589 (Gillespie et al., 2007; Duncombe \& Therriault, 2017). From an invasive species management 590 perspective, this shows that there may be more green crabs in an area than is suggested by catch 591 data alone, emphasising the importance of not relying exclusively on catch data to estimate green 592 crab populations in invaded areas.

Step 6-Green crab must not exit the trap

Over the $73 \mathrm{~h}$ of video we analyzed, we did not observe a single escape from the Fukui 596 trap, demonstrating that although it is difficult to enter the trap, once inside there is very little 597 chance of a green crab escaping. However, it should be noted that we were not always able to retrieve the trap before the end of the video recording. Therefore, our final catch numbers do not

599 necessarily correspond to what was observed in the video. Given the low rate of successful entry, 600 the benefits of a highly secure trap that prevents escapes are lost when compared to the potential 601 number of green crabs that could be captured if the entrance to the trap was less restrictive to 602 begin with. To be more efficient, the Fukui trap needs to have a balance between effective catch 603 and the risk of potential escapes. 
605

606

607

608

609

610

611

612

613

614

615

616

617

618

619

620

621

622

623

624

625

626

627

\section{3 - Regional performance of the Fukui trap}

The green crab is considered a global invader, and has established populations on almost every continent around the globe (Yamada, 2001; Carlton \& Cohen, 2003). The expansive distribution of invasive green crab populations in North America alone, coupled with variations in genetic origin, suggests that there may not be a one-size-fits-all approach when responding to green crab invasions. That being said, the Fukui trap is being used on both the east (Matheson \& Gagnon, 2012; Rossong et al., 2012; McNive, Quijon \& Mitchell, 2013; Best, McKenzie \& Couturier, 2014) and west (Yamada et al., 2005, 2008; Jensen, McDonald \& Armstrong, 2007; Duncombe \& Therriault, 2017) coasts of North America, and remains the trap of choice for green crab mitigation due to its relative effectiveness, durability, and ease-of-use compared with other traps (Cynthia H. McKenzie, personal communication).

In Newfoundland, we anticipated that genetic differences in aggression and foraging behaviour might influence how green crabs interacted with the Fukui trap. However, we saw little variation in the performance of the Fukui trap from one study site to the next, and there was no statistically significant differences in trap efficiency between regions. This suggests that the factors that contribute to high entry attempt failure, and therefore limit catch efficiency, are underlying problems with the Fukui trap itself and are not influenced by behavioural variations in local green crab populations. If these underlying factors that limit catch efficiency can be addressed and corrected, then we expect that catch efficiency can be improved wherever Fukui traps are being utilized as a mitigation tool, regardless of genetic differences and regional green crab characteristics.

\section{4 - Efficiency and modification}


Only $16.0 \%$ of green crab entry attempts were successful, demonstrating that there is

629

630

631

632

633

634

635

636

638

much room for improvement in the performance and efficiency of the Fukui trap. Still, the Fukui trap is a common choice for green crab mitigation across Canada, and intensive trapping has proven to be an effective technique for reducing green crab populations (Gillespie et al., 2007; DFO, 2011a,b). It has been shown that continuous trapping can cause a demographic shift towards a younger population, with reduced body mass and reproductive potential (Duncombe $\&$ Therriault, 2017). Furthermore, continuous trapping can gradually reduce the average carapace width of green crabs in an invaded area by removing larger individuals from the population (Duncombe \& Therriault, 2017). This size decrease causes a shift in the ecological role of green crabs from primary predators, to potential prey for native shorebirds and crustaceans (DFO, 2011a). Furthermore, it has been shown that in areas where intensive trapping has occurred that the abundance of native species increases over time (e.g. rock crabs) (DFO, 2011a). Therefore, despite the limitations of the Fukui trap, it remains an important tool for reducing green crab populations in invaded ecosystems.

Based on our video observations, we believe there is scope to develop an improved Fukui trap that will facilitate the entry of green crabs into the trap. The problems associated with the design of the Fukui trap are predominately mechanical issues, and can likely be addressed through modifications. We propose three simple modifications that would likely improve the efficiency of the Fukui trap: First, the entry slit of the trap needs to be expanded slightly to allow green crabs to pass through more freely. This could be accomplished using string, cable ties etc. to secure the entry slits in a partially-opened position. Second, the Fukui trap entrance tunnels could be constructed using a smaller mesh that would prevent green crabs from becoming entangled or snagged during entry attempts. This could quickly be accomplished by overlaying 
651 the existing mesh with a finer mesh, and securing it in place. Finally, green crabs would benefit

652 from a fixed object on the inside of the Fukui trap that they could grasp in order to assist in

653 pulling their bodies through the entry slit. This could be accomplished by simply affixing a piece

654 of string, wire, mesh etc. across the width of the trap, on the interior side of the entrance slit. In

655 addition to these design modifications, future studies could also test whether the addition of

656 artificial lighting to the Fukui trap can be used to improve green crab CPUE, as seen with snow

657 crab (Chionoecetes opilio) traps (Nguyen et al., 2017).

Any modifications to the Fukui trap would have to be tested to quantify the trade-offs of an altered trap design. If modifications were to alter the restrictive entry slit, this could increase the proportion of successful green crab entry attempts, but it could also impact retention (i.e.

661 cause an increase in green crab exits). Furthermore, it is possible that a Fukui trap modified to 662 capture more green crabs, may also catch more bycatch. However, if these design modifications 663 are found to be effective, and the negative trade-offs are minimal, then this will greatly increase 664 the number of green crabs that are removed from invaded ecosystems during mitigation efforts. 665 Additionally, a more efficient Fukui trap will mean higher CPUE, maximizing trap usage for 666 mitigation and control. Ultimately, a more efficient Fukui trap will help to control green crab 667 populations in order to preserve the function and integrity of ecosystems invaded by the green 668 crab.

\section{Conclusions}

Our study represents the first formal investigation into the performance of the Fukui trap

672 as a mitigation tool for the invasive green crab in Newfoundland. Our use of underwater video

673 was a novel approach that allowed us to accurately determine the capture efficiency of these 
674 traps in a way that would be unachievable from catch data alone. Through the use of underwater

675 video, we were able to gain insight into the efficiency of the Fukui trap, as well as the

676 interactions that occur around and inside these traps as they are actively fished for green crab in-

677 situ. Although our results revealed the rate of successful entries into the Fukui trap was low, we

678 are confident that the mechanical inefficiencies of the trap can be addressed through simple

679 modifications that will increase their CPUE. Furthermore, we were able to conclude that the

680 underlying mechanisms contributing to low capture efficiency remained consistent regardless of

681 the region or the local green crab population. The versatility of the Fukui trap as a control

682 method for green crabs has contributed to its widespread use on both the east and west coast of

683 Canada. Therefore, if the performance and efficiency of the Fukui trap can be improved then this 684 will benefit green crab mitigation efforts wherever these traps are being used.

\section{Acknowledgements}

We thank many individuals for their assistance and contributions to this project. We

688 thank DFO for providing the Fukui traps and bait used in this study. We thank staff at the Marine

Institute's Centre for Sustainable Aquatic Resources (Terry Bungay and George Legge) for

assistance in constructing and testing the camera apparatus. We acknowledge DFO staff from the

691 Aquatic Invasive Species program and the Ecological Sciences Section (Kyle Matheson, Ashley

692 Bungay, Haley Lambert, Dave Forsey, Rebecca Raymond, and Bob Whalen) for their assistance

693 with fieldwork, as well as DFO Fisheries Patrol Officers (Sherry Pittman and Kim Sheehan) for

694 assistance with fieldwork in the Bay of Islands, NL. We also acknowledge the MUN Field

695 Services team (Andrew Perry, Zach Ryan, and George Bishop) for their assistance in the field.

696 We thank Sheldon Peddle with ACAP Humber Arm for providing us with additional bait, and for 
697 delivering replacement camera equipment while in the field. We thank Bob Hooper with the

698 MUN Bonne Bay Marine Station for providing access to a boat, field resources, and

699 accommodation. For fieldwork conducted in Fox Harbour we thank Gerard O'Leary for access to

700 private property for the deployment of our camera equipment. Finally, we thank one anonymous

701 reviewer, Leslie Roberson, and our academic editor, Dr. Donald Kramer for their constructive

702 reviews of our manuscript, which greatly enhanced the final paper. 
703

704

705

706

707

708

709

710

711

712

713

714

715

716

717

718

719

720

721

722

723

\section{References}

Archdale MV., Kariyazono L., Añasco CP. 2006. The effect of two pot types on entrance rate and entrance behavior of the invasive Japanese swimming crab Charybdis japonica. Fisheries Research 77:271-274. DOI: 10.1016/j.fishres.2005.11.012.

Bacheler NM., Schobernd CM., Schobernd ZH., Mitchell WA., Berrane DJ., Kellison GT., Reichert MJM. 2013. Comparison of trap and underwater video gears for indexing reef fish presence and abundance in the southeast United States. Fisheries Research 143:81-88. DOI: 10.1016/j.fishres.2013.01.013.

Barber JS., Cobb JS. 2009. Qualitative observations of Dungeness crabs, Cancer magister, in and around traps: evidence of resource guarding and clustering. Marine and Freshwater Behaviour and Physiology 42:135-146. DOI: 10.1080/10236240902860011.

Bates D., Mächler M., Bolker B., Walker S., Christensen RHB., Singmann H., Dai B., Grothendieck G., Green P. 2017. Package "Ime4”. R package version 1.1-13, https://github.com/lme4/lme4/.

Bax N., Williamson A., Aguero M., Gonzalez E., Geeves W. 2003. Marine invasive alien species: a threat to global biodiversity. Marine Policy 27:313-323. DOI: 10.1016/S0308$597 X(03) 00041-1$.

Bergshoeff JA., Zargarpour N., Legge G., Favaro B. 2017. How to build a low-cost underwater camera housing for aquatic research. Facets 2:150-159. DOI: 10.1139/facets-2016-0048.

Berrill M. 1982. The life cycle of the green crab Carcinus maenas at the northern end of its range. Journal of Crustacean Biology 2:31-39. 
724 Best K., McKenzie CH., Couturier C. 2014. Investigating mitigation of juvenile European green crab Carcinus maenas from seed mussels to prevent transfer during Newfoundland mussel aquaculture operations. Management of Biological Invasions 5:255-262.

727

728

729

730

731

732

733

Beukema JJ. 1991. The abundance of shore crabs Carcinus maenas (L.) on a tidal flat in the Wadden Sea after cold and mild winters. Journal of Experimental Marine Biology and Ecology 153:97-113. DOI: 10.1016/S0022-0981(05)80009-7.

Blakeslee AMH., McKenzie CH., Darling JA., Byers JE., Pringle JM., Roman J. 2010. A hitchhiker's guide to the Maritimes: anthropogenic transport facilitates long-distance dispersal of an invasive marine crab to Newfoundland. Diversity and Distributions 16:879891. DOI: $10.1111 / \mathrm{j} .1472-4642.2010 .00703 . x$.

Carlton JT., Cohen AN. 2003. Episodic global dispersal in shallow water marine organisms: the case history of the European shore crabs Carcinus maenas and C. aestuarii. Journal of Biogeography 30:1809-1820. DOI: 10.1111/j.1365-2699.2003.00962.x.

Cohen AN., Carlton JT., Fountain MC. 1995. Introduction, dispersal and potential impacts of the green crab Carcinus maenas in San Francisco Bay, California. Marine Biology 122:225237.

Crisp DJ. 1964. The effects of the severe winter of 1962-63 on marine life in Britain. British Ecological Society 33:165-210.

Crothers J. H. 1968. The biology of the shore crab Carcinus maenas (L.) 2. The life of the adult crab. Field Studies 2:579-614.

Curtis LJF., Curtis DL., Matkin H., Thompson M., Choi F., Callow P., Gillespie GE., Terriault 
TW., Pearce CM. 2015. Evaluating transfers of harvested shellfish products, from the west to the east coast of Vancouver Island, as a potential vector for European green crab (Carcinus Maenus) and other non-indigenous invertebrate species. DFO Can. Sci. Advis. Sec. Res. Doc. 2015/014:vi + 74 p.

DFO. 2011a. Ecological assessment of the invasive European green crab (Carcinus maenas) in Newfoundland 2007-2009. DFO Can. Sci. Advis. Sec. Sci. Advis. Rep.:2011/033.

DFO. 2011b. Proceedings of the Regional Advisory Process on green crab, Carcinus maenas, populations and mitigations in the Newfoundland and Labrador region. DFO Can. Sci. Advis. Sec. Proceed. Ser. 2011/020.

DFO. 2016. Oceanographic conditions in the Atlantic zone in 2015. DFO Can. Sci. Advis. Sec. Sci. Advis. Rep.:2016/041.

Duncombe LG., Therriault TW. 2017. Evaluating trapping as a method to control the European green crab, Carcinus maenas, population at Pipestem Inlet, British Columbia. Management of Biological Invasions 8:235-246.

Favaro B., Duff SD., Côté IM. 2013. A trap with a twist: evaluating a bycatch reduction device to prevent rockfish capture in crustacean traps. ICES Journal of Marine Science 70:114122.

Favaro B., Duff SD., Côté IM. 2014. Density-dependent catchability of spot prawns (Pandalus platyceros) observed using underwater video. The Journal of Ocean Technology 9:84-98.

Favaro B., Lichota C., Côté IM., Duff SD. 2012. TrapCam: an inexpensive camera system for studying deep-water animals. Methods in Ecology and Evolution 3:39-46. DOI: 
766

767

768

769

770

771

772

773

774

775

776

777

778

779

780

781

782

783

784

785

786

10.1111/j.2041-210X.2011.00128.x.

Gillespie GE., Norgard TC., Anderson ED., Haggarty DR., Phillips AC. 2015. Distribution and biological characteristics of European green crab, Carcinus maenas, in British Columbia, 2006 - 2013. Canadian Technical Report of Fisheries and Aquatic Sciences 3120:88p.

Gillespie GE., Phillips AC., Paltzat DL., Therriault TW. 2007. Status of the European green crab, Carcinus maenas, in British Columbia - 2006. Canadian Technical Report of Fisheries and Aquatic Sciences 2700:39 p.

He P. 2003. Swimming behaviour of winter flounder (Pleuronectes americanus) on natural fishing grounds as observed by an underwater video camera. Fisheries Research 60:507514. DOI: 10.1016/S0165-7836(02)00086-3.

Jeffery NW., DiBacco C., Van Wyngaarden M., Hamilton LC., Stanley RRE., Bernier R., FitzGerald J., Matheson K., McKenzie CH., Nadukkalam Ravindran P., Beiko R., Bradbury IR. 2017. RAD sequencing reveals genomewide divergence between independent invasions of the European green crab (Carcinus maenas) in the Northwest Atlantic. Ecology and Evolution:1-12. DOI: 10.1002/ece3.2872.

Jensen GC., McDonald PS., Armstrong DA. 2007. Biotic resistance to green crab, Carcinus maenas, in California bays. Marine Biology 151:2231-2243. DOI: 10.1007/s00227-0070658-4.

Joseph V., Schmidt AL., Gregory RS. 2013. Use of eelgrass habitats by fish in eastern Canada. Canadian Scientific Advisory Secretariat Science Research Document 2012/138:ii + 12p.

Jury SH., Howell H., O’Grady DF., Watson WH., Jury, S.H., Howell, H., O’Grady, D.F.O. \& 
Watson III WH. 2001. Lobster trap video: in situ video surveillance of the behaviour of Homarus americanus in and around traps. Marine and Freshwater Research 52:1125-1132.

Kahle D., Wickham H. 2013. ggmap: Spatial Visualization with ggplot2. The R Journal 5:144161.

Kersey Sturdivant S., Clark KL. 2011. An evaluation of the effects of blue crab (Callinectes sapidus) behavior on the efficacy of crab pots as a tool for estimating population abundance. Fishery Bulletin 109:48-55.

Klassen G., Locke A. 2007. A biological synopsis of the European green crab, Carcinus maenas. Canadian Manuscript Report of Fisheries and Aquatic Sciences 2818:1-82.

Lodge DM., Williams S., MacIsaac HJ., Hayes KR., Leung B., Reichard S., Mack RN., Moyle PB., Smith M., Andow DA., Carlton JT., McMichael A. 2006. Biological invaions: recommendations for U.S. policy and management. Ecological Applications 16:2035-2054. DOI: $10.1890 / 04-0922$.

Lowe S., Browne M., Boudjelas S., De Poorter M. 2000. 100 of the world's worst invasive alien species: a selection from the global invasice species database. Invasive Species Specialist group (ISSG), specialist group of the Species Survival Commission (SSC) of the World, Conservation Union (IUCN).

Matheson K., Gagnon P. 2012. Temperature mediates non-competitive foraging in indigenous rock (Cancer irroratus Say) and recently introduced green (Carcinus maenas L.) crabs from Newfoundland and Labrador. Journal of Experimental Marine Biology and Ecology 414415:6-18. DOI: 10.1016/j.jembe.2012.01.006. 
808 Matheson K., McKenzie CH. 2014. Predation of sea scallops and other indigenous bivalves by 809 invasive green crab, Carcinus maenas, from Newfoundland, Canada. Journal of Shellfish $810 \quad$ Research 33:495-501. DOI: 10.2983/035.033.0218.

811 Matheson K., McKenzie CH., Gregory RS., Robichaud DA., Bradbury IR., Snelgrove PVR., 812 Rose GA. 2016. Linking eelgrass decline and impacts on associated fish communities to 813 European green crab Carcinus maenas invasion. Marine Ecology Progress Series 548:3145. DOI: $10.3354 / \mathrm{meps} 11674$.

815 McKenzie CH., Han G., He M., Wells T., Maillet G. 2011. Alternate ballast water exchange 816 zones for the Newfoundland and Labrador region - an aquatic invasive species risk assessment based on oceanographic modelling, ecologically and biologically significant

McNive MA., Quijon PA., Mitchell AW. 2013. Composition and distribution of the European 821 green crab in Prince Edward Island, Canada. Journal of Animal Science 3:295-298. areas and the sustainability of fisheries and aquacul. DFO Can. Sci. Advis. Sec. Res. Doc. 2010/087:viii + 39 p.

Meintzer P., Walsh P., Favaro B. 2017. Will you swim into my parlour? In situ observations of Atlantic cod (Gadus morhua) interactions with baited pots, with implications for gear design. PeerJ 5:e2953. DOI: 10.7717/peerj.2953.

Miller RJ. 1978. Entry of Cancer productusto to baited traps. ICES Journal of Marine Science 38:220-225. DOI: 10.1093/icesjms/38.2.220.

Murray LG., Seed R. 2010. Determining whether catch per unit effort is a suitable proxy for relative crab abundance. Marine Ecology Progress Series 401:173-182. DOI: 10.3354/meps08415. 
830 Nguyen TX., Winger PD., Legge G., Dawe EG., Mullowney DR. 2014. Underwater observations

Orth RJ., Carruthers TJB., Dennison WC., Duarte CM., Fourqurean JW., Heck KL., Hughes

Nguyen KQ., Winger PD., Morris C., Grant SM. 2017. Artificial lights improve the catchability of snow crab ( Chionoecetes opilio ) traps. Aquaculture and Fisheries 2:124-133. DOI: 10.1016/j.aaf.2017.05.001. northeast Newfoundland. Fisheries Research 156:9-13. DOI: 10.1016/j.fishres.2014.04.013.

AR., Kendrick GA., Kenworthy WJ., Olyarnik S., Short FT., Waycott M., Williams SL.

2006. A global crisis for seagrass ecosystems. Bioscience 56:987-996. DOI: 10.1641/00063568(2006)56[987:agcfse]2.0.co;2.

841 Pinhero J., Bates D., Debroy S., Sarkar D., R Core Team. 2017. nlme: linear and nonlinear mixed

Pintor LM., Sih A., Bauer ML., Pintor LM., Sih A., Bauer ML. 2008. Differences in aggression, activity and boldness between native and introduced populations of an invasive crayfish. Oikos 117:1629-1636.

R Core Team. 2015. R: A language and environment for statistical computing. R Foundation for comparison of four gambusia species. Biological Invasions 6:379-391. DOI: 10.1023/B:BINV.0000034618.93140.a5. 
851 Robbins WD., Peddemors VM., Broadhurst MK., Gray CA. 2013. Hooked on fishing?

852

853

854

855

856

857

858

859

860

861

862

863

864

865

866

867

868

869

870

871

872

Recreational angling interactions with the Critically Endangered grey nurse shark

Carcharias taurus in eastern Australia. Endangered Species Research 21:161-170. DOI:

10.3354/esr00520.

Roman J. 2006. Diluting the founder effect: cryptic invasions expand a marine invader's range. Proceedings of the Royal Society B: Biological Sciences 273:2453-2459. DOI: 10.1098/rspb.2006.3597.

Ropes JW. 1968. The feeding habits of the green crab, Carcinus maenas (L.). Fishery Bulletin 67:183-203.

Rossong MA., Quijón PA., Snelgrove PVR., Barrett TJ., McKenzie CH., Locke A. 2012. Regional differences in foraging behaviour of invasive green crab (Carcinus maenas) populations in Atlantic Canada. Biological Invasions 14:659-669. DOI: 10.1007/s10530011-0107-7.

Rossong MA., Williams PJ., Comeau M., Mitchell SC., Apaloo J. 2006. Agonistic interactions between the invasive green crab, Carcinus maenas (Linnaeus) and juvenile American lobster, Homarus americanus (Milne Edwards). Journal of Experimental Marine Biology and Ecology 329:281-288. DOI: 10.1016/j.jembe.2005.09.007.

Say T. 1817. An account of the crustacea of the United States. Journal of the Academy of Natural Sciences of Philadelphia 1:57-63.

Shelton RGJ., Mackie AM. 1971. Studies on the chemical preferences of the shore crab, Carcinus maenas (L.). Journal of Experimental Marine Biology and Ecology 7:41-49. DOI: 10.1016/0022-0981(71)90003-7. 
873 Souza AT., Ilarri MI., Campos J., Marques JC., Martins I. 2011. Differences in the neighborhood: Structural variations in the carapace of shore crabs Carcinus maenas (Decapoda: Portunidae). Estuarine, Coastal and Shelf Science 95:424-430. DOI: 10.1016/j.ecss.2011.06.021.

Underwood MJ., Winger PD., Fernö A., Engås A. 2015. Behavior-dependent selectivity of yellowtail flounder (Limanda ferruginea) in the mouth of a commercial bottom trawl. Fishery Bulletin 113:430-441. DOI: 10.7755/FB.113.6.

Underwood M., Winger PD., Legge G. 2012. Development and evaluation of a new high definition self-contained underwater camera system to observe fish and fishing gears in situ. The Journal of Ocean Technology 7:59-70.

Vazquez Archdale M., Anraku K., Yamamoto T., Higashitani N. 2003. Behavior of the Japanese rock crab "Ishigani" Charybdis japonica towards two collapsible baited pots: Evaluation of capture effectiveness. Fisheries Science 69:785-791. DOI: 10.1046/j.14442906.2003.00687.x.

Watson W., Jury SH. 2013. The relationship between American lobster catch, entry rate into traps and density. Marine Biology Research 9:59-68. DOI: 10.1080/17451000.2012.727430.

Weis JS. 2010. The role of behavior in the success of invasive crustaceans. Marine and Freshwater Behaviour and Physiology 43:83-98. DOI: 10.1080/10236244.2010.480838.

Welch WR. 1968. Changes in abundance of green crab, Carcinus maenas (L.), in relation to recent temperature changes. United States Fish and Wildlife Service Fishery Bulletin $67: 337-345$. 
895 Williams AB. 1984. Shrimps, Lobsters, and Crabs of the Altantic Coast of the Eastern United 896 States, Maine to Florida. Washington, DC. DOI: 10.2307/1352125.

897 Williams K., De Robertis A., Berkowitz Z., Rooper C., Towler R. 2014. An underwater stereo898 camera trap. Methods in Oceanography 11:1-12. DOI: 10.1016/j.mio.2015.01.003.

899 Yamada S. 2001. Global Invader: The European Green Crab. Corvallis, Oregon: Oregon Sea $900 \quad$ Grant.

901 Yamada SB., Dumbauld BR., Kalin A., Hunt CE., Figlar-Barnes R., Randall A. 2005. Growth 902 and persistence of a recent invader Carcinus maenas in estuaries of the northeastern Pacific. 903 Biological Invasions 7:309-321. DOI: 10.1007/s10530-004-0877-2.

904 Yamada S., Gillespie GGE., Behrens Yamada S., Gillespie GGE. 2008. Will the European green 905 crab (Carcinus maenas) persist in the Pacific Northwest? ICES Journal of Marine Science $906 \quad 65: 725-729$. DOI: 10.1093/icesjms/fsm191.

907 Yamada SB., Kosro PM. 2010. Linking ocean conditions to year class strength of the invasive 908 European green crab, Carcinus maenas. Biological Invasions 12:1791-1804. DOI:

909 10.1007/s10530-009-9589-y. 
Figure 1

A visual representation of the six steps required for a green crab to be captured.

The numbers indicate the step in the capture process: 1) Presence, 2) Detection, 3) Approach, 4) Attempt, 5) Capture, 6) Exit.

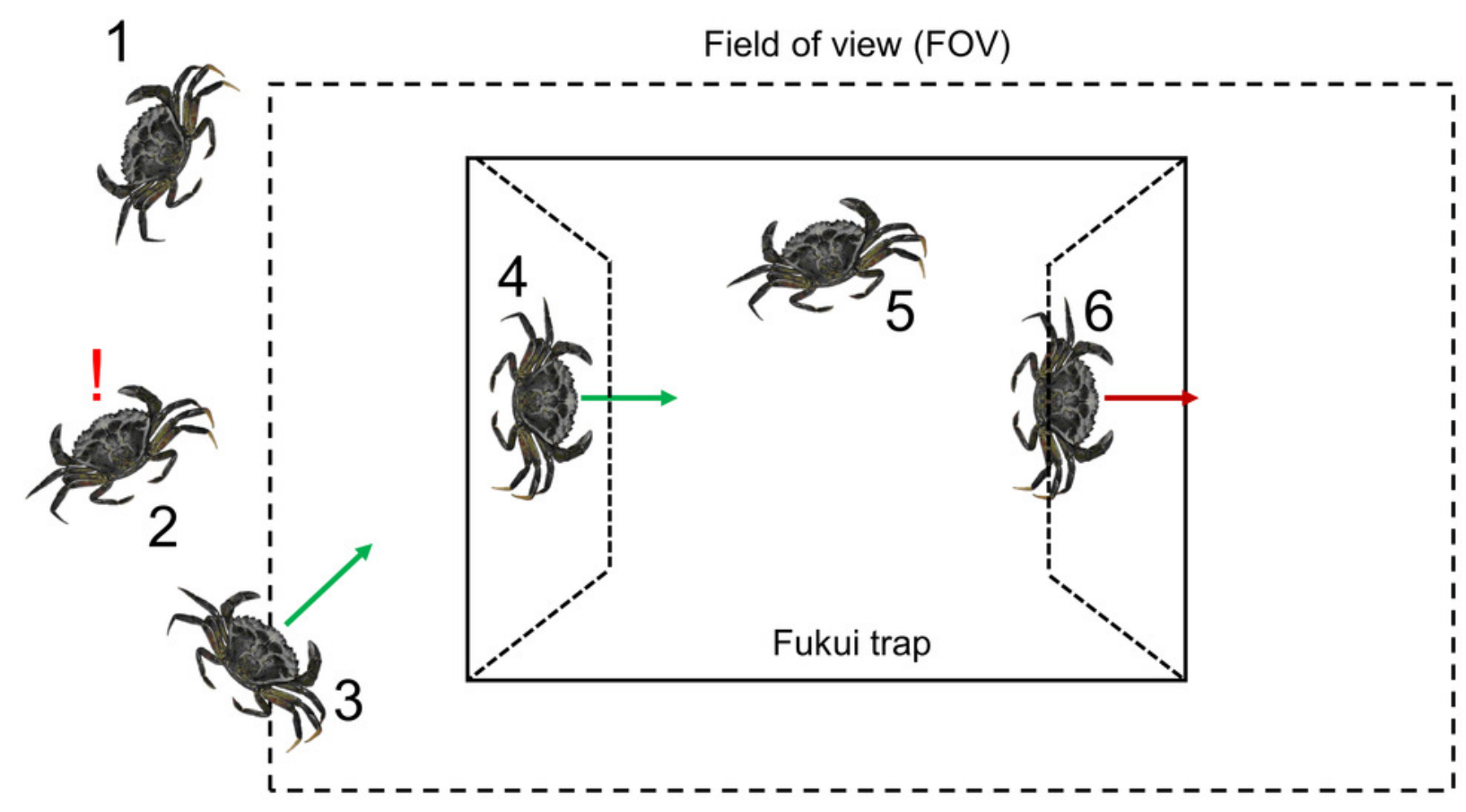




\section{Figure 2}

The camera frame constructed around a Fukui trap and its field of view.

A top-down view of the Fukui trap recorded during a daytime deployment (top left) and overnight deployment (bottom left). The entire camera apparatus mounted to a Fukui trap (right).
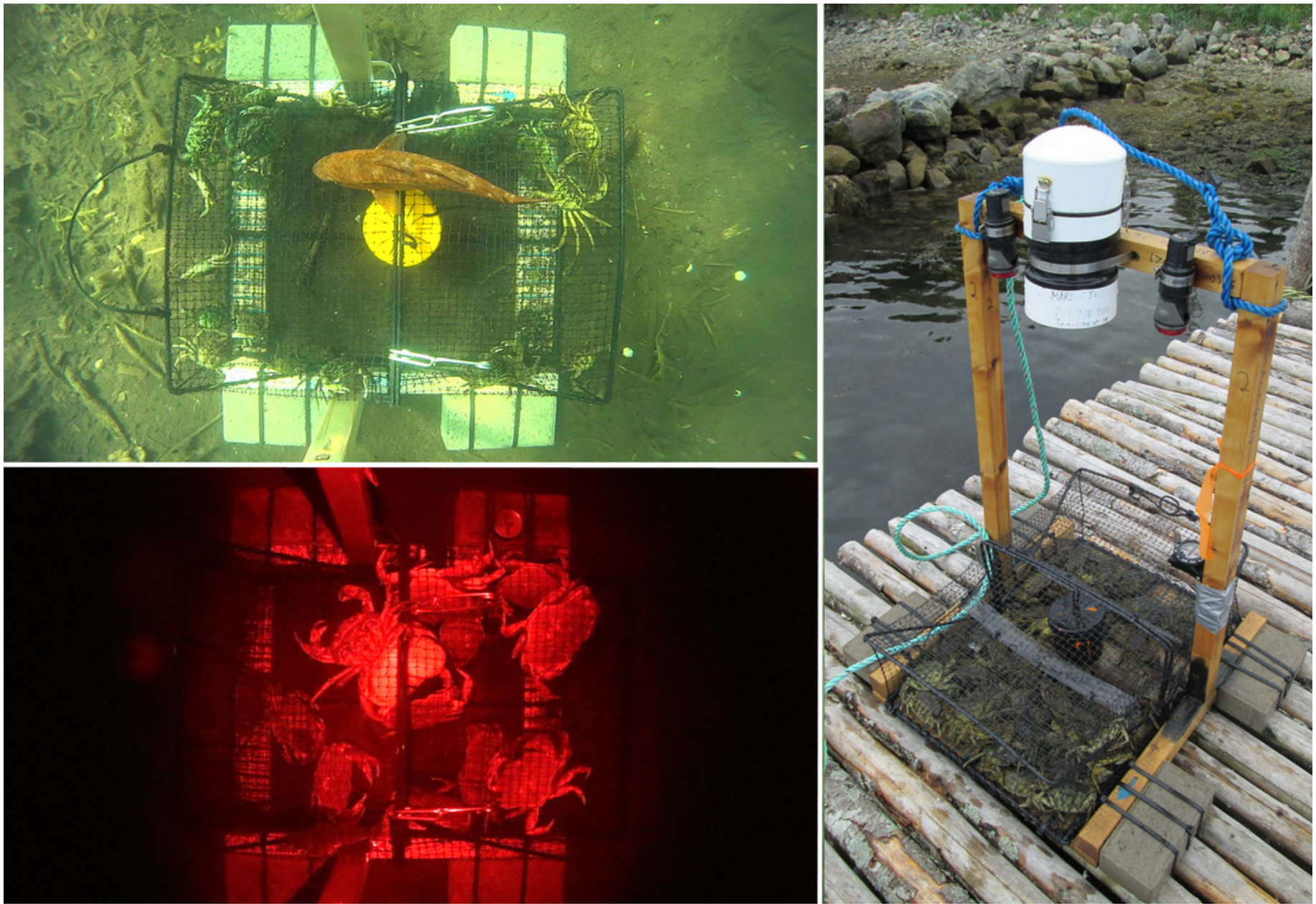


\section{Figure 3}

Map of 2015 and 2016 study sites across Newfoundland.

$Q$

Site included Bonne Bay (BB), Boat Harbour (BH), Fair Haven (FH), Little Harbour East (LHE), Penguin Arm (PA), Little Port Harmon (PH), and Fox Harbour (FX). Map imagery (c) 2017 TerraMetrics.

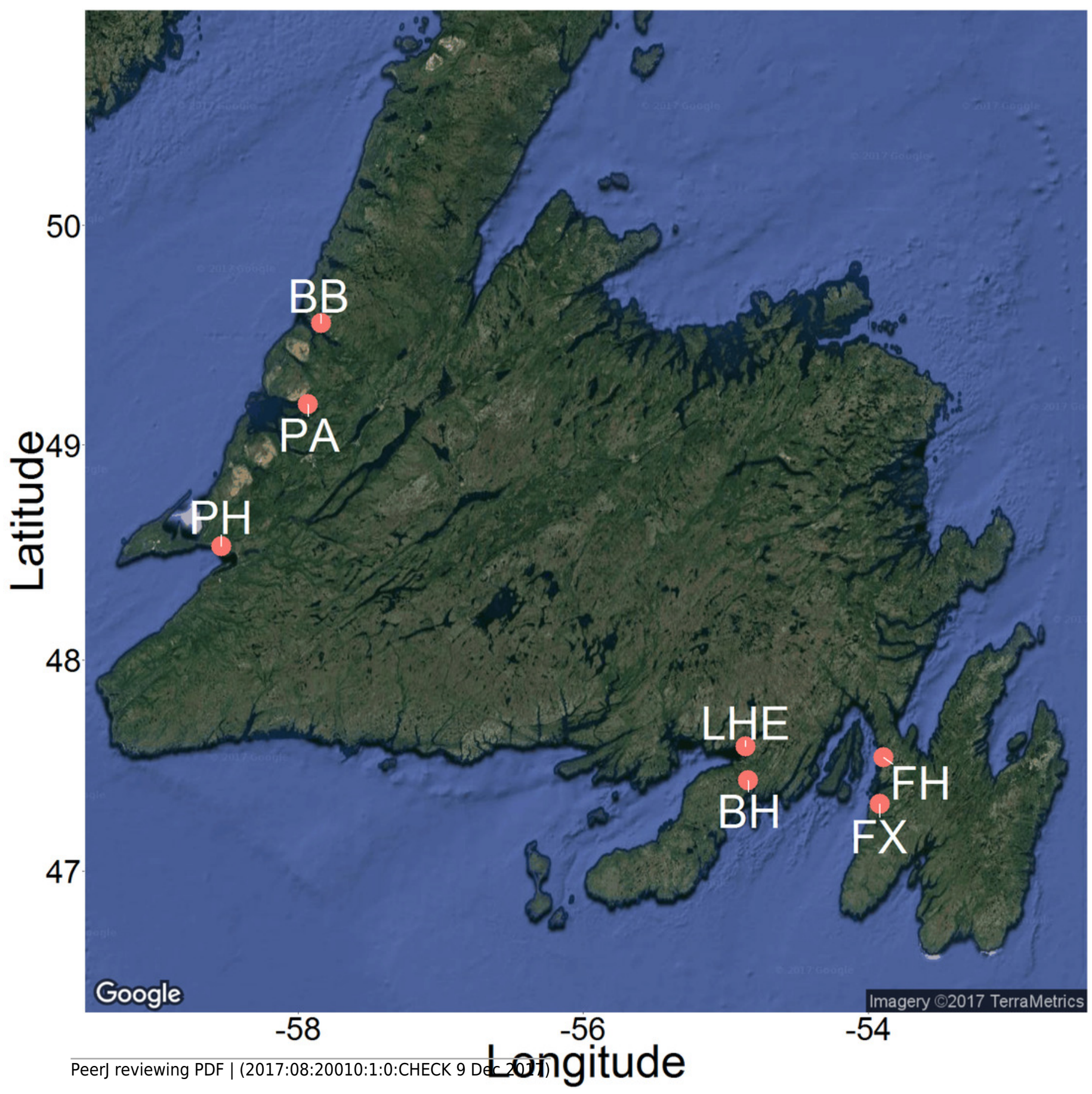


Figure 4

Plots comparing green crab catch and fishing duration between Fair Haven, NL and Little Port Harmon, NL.

Scatterplot $A$ and $B$ show the duration and number of green crabs captured for each deployment at Fair Haven $(A)(n=16)$ and Little Port Harmon $(B)(n=13)$, respectively. Boxplot $\mathrm{C}$ shows the mean deployment duration at Fair Haven and Little Port Harmon. Boxplot D shows the mean green crab catch per Fukui trap at Fair Haven and Little Port Harmon.
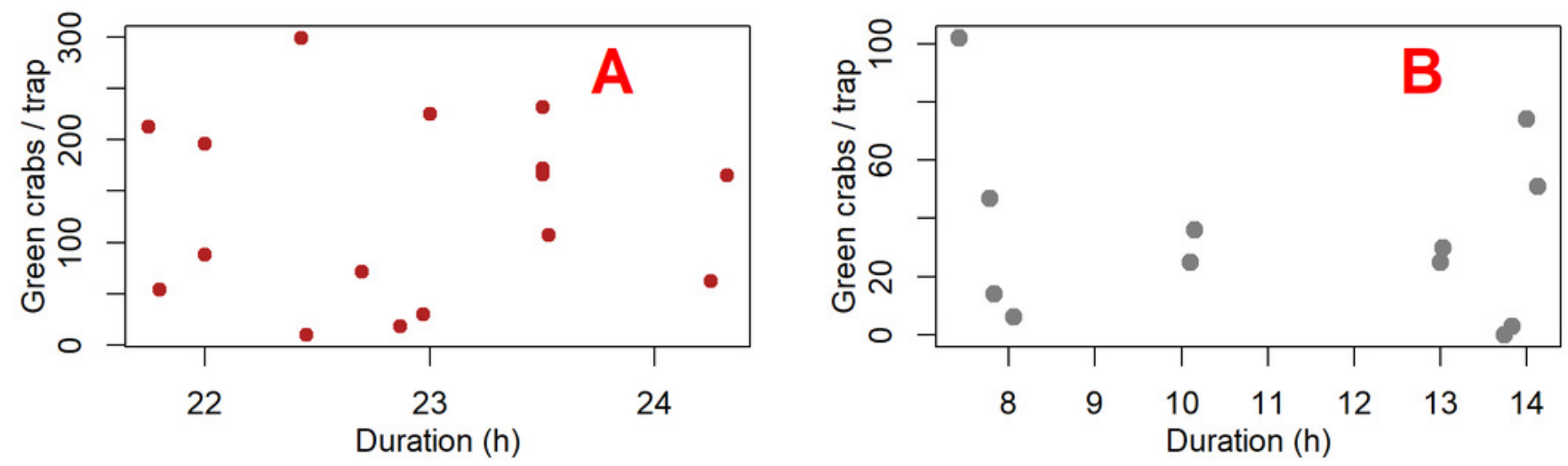

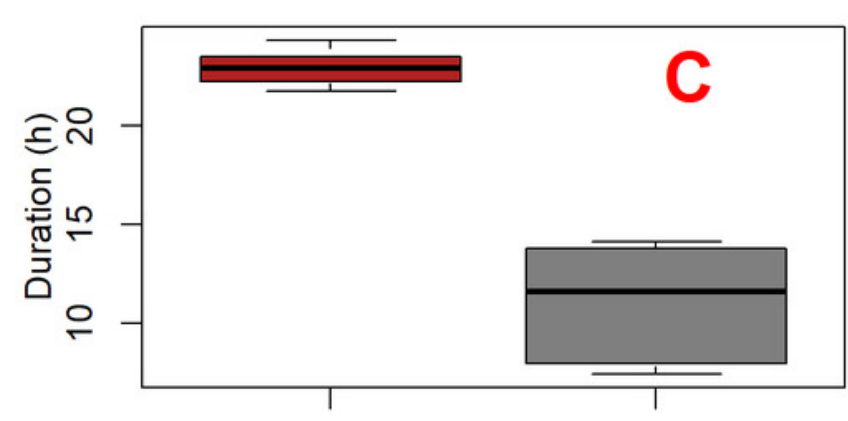

Fair Haven, NL Little Port Harmon, NL

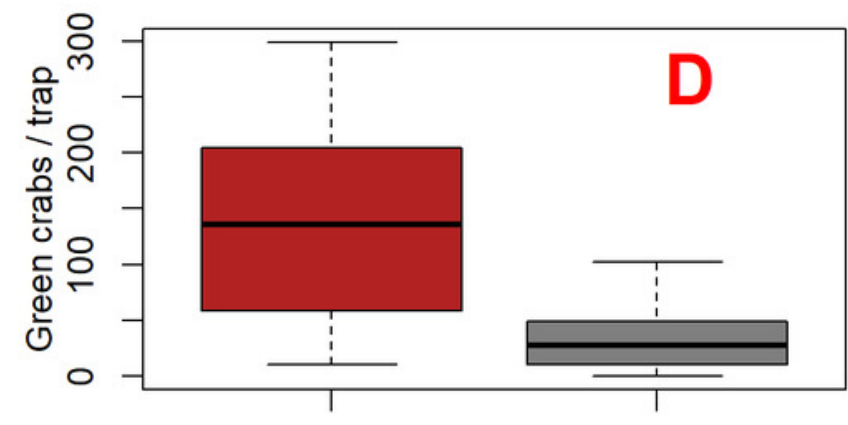

Fair Haven, NL Little Port Harmon, NL 


\section{Figure 5}

A screen shot from a video recording showing the top-down view of a Fukui trap as it actively fishes in situ.

Approaches were recorded every time an animal entered the FOV from direction 1, 2, 3, or 4 . The entrance tunnels are outlined with red lines. The dotted red line indicates the entry slits into the trap.

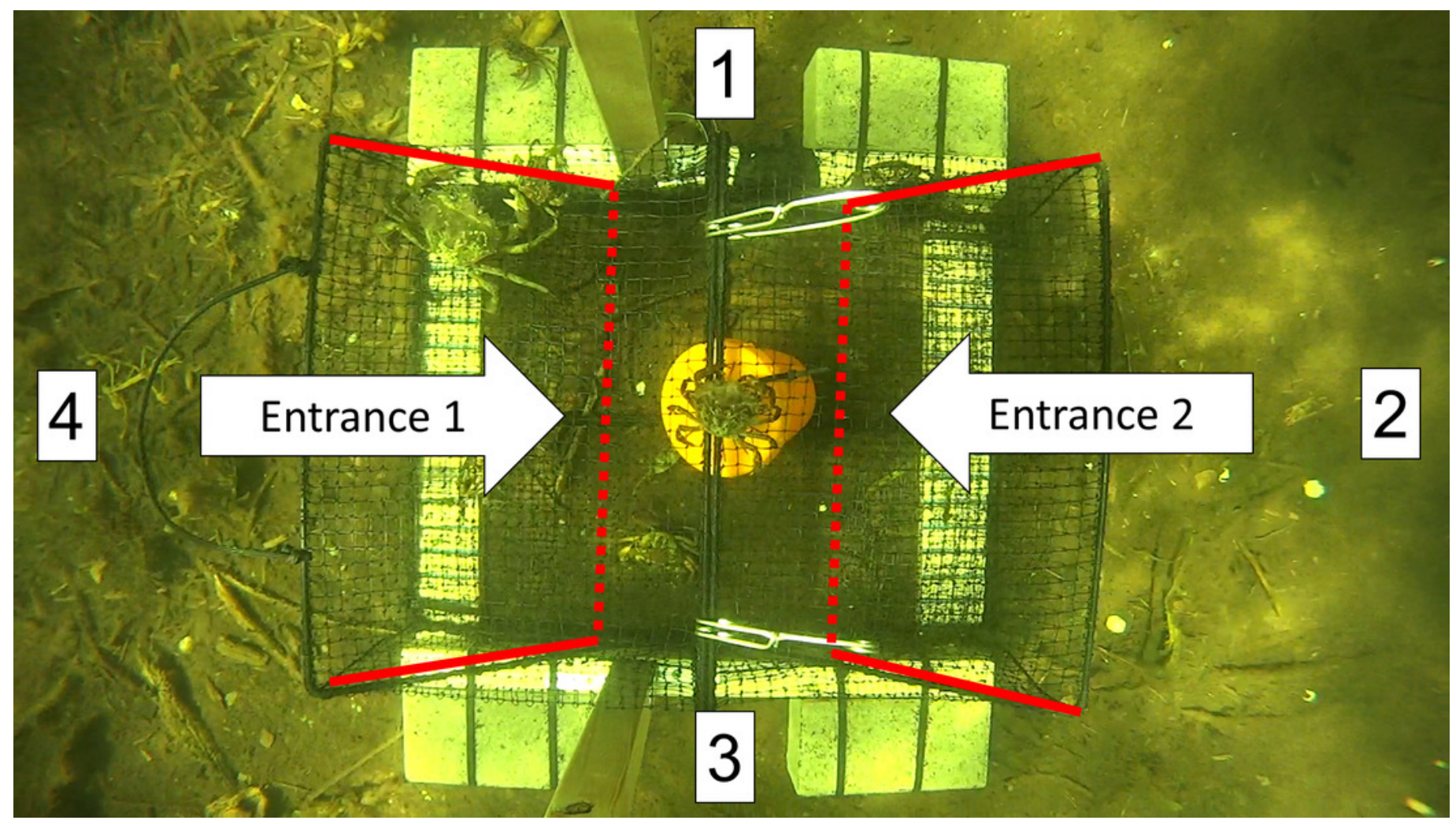


Figure 6

Green crab accumulation over the course of each trap deployment $(n=8)$.

Green crab approaches (A), entry attempts (B), and accumulation in the Fukui trap (C). We did not observe any exits; therefore, panel $\mathrm{C}$ represents both the number of successful entries, and the number of green crabs in the trap. Each coloured line (Video ID) represents the individual deployment of a camera-equipped Fukui trap at either Fair Haven (FH) (redorange colour scheme), Little Port Harmon (PH) (blue colour scheme), or Fox Harbour (FX) (green colour scheme).
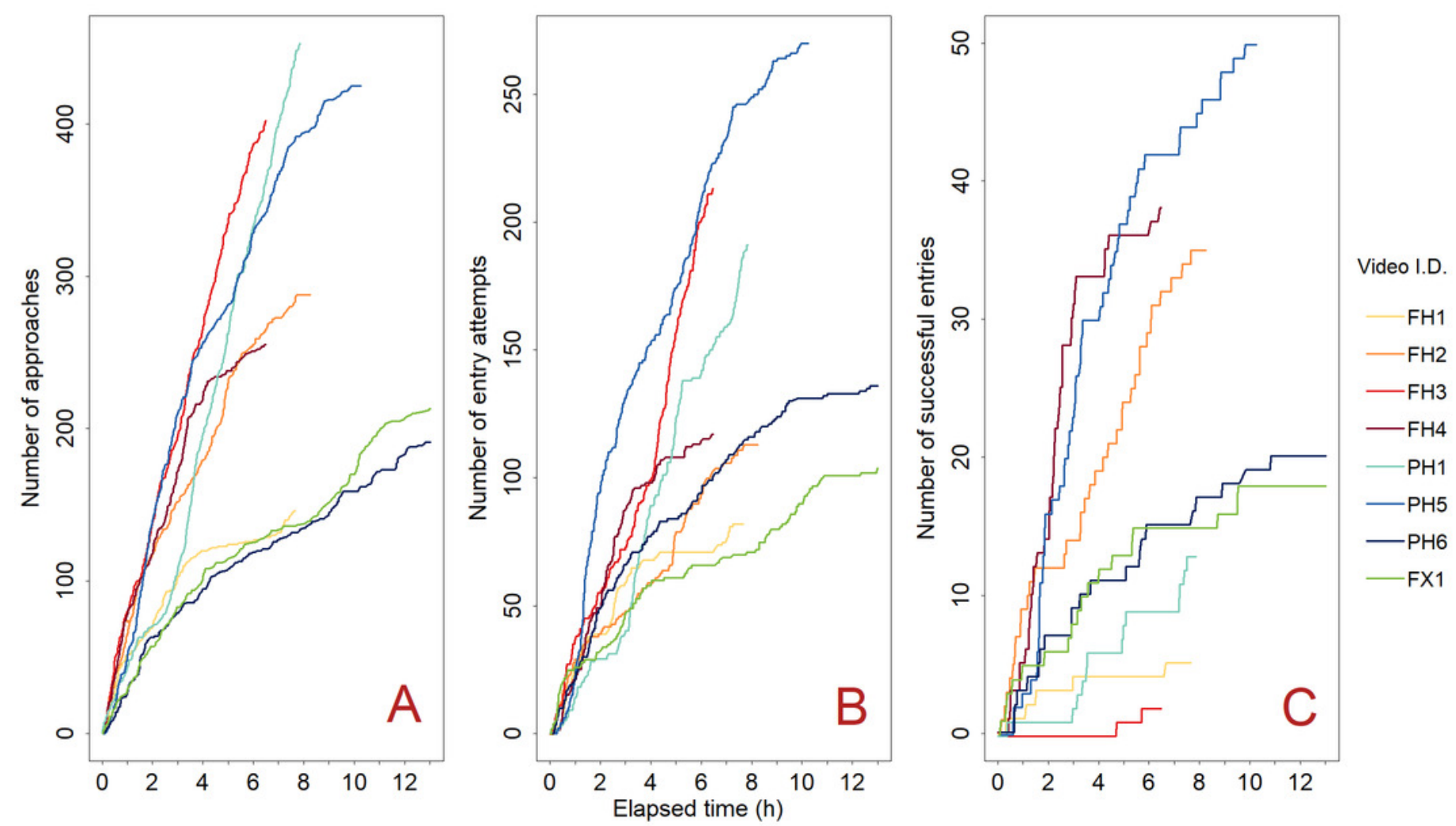


\section{Figure 7}

The proportional outcome and average time taken for all green crab entry attempts into the Fukui trap.

Left - The proportion of all green crab entry attempts that were successful and that were failures. The failed proportion is subdivided according to the four most common reasons for failure: agonistic behaviour (AGON), partial entry (PE), full entry (FE), and difficulty completing entry (DCE). The total number ( $n$ ) of entry attempts for each is given. Right - A boxplot illustrating the average time (seconds, log scale used) for each type of entry attempt. The solid black line within the box depicts the median. The lower and upper hinges of the box correspond to the first and third quartiles, respectively. The upper whisker extends to the largest value no further than 1.5 times the inter-quartile range (1.5*IQR). The lower whisker extends to the smallest value no further than 1.5*IQR. Any data points beyond these whiskers are considered outliers, and are plotted individually. 

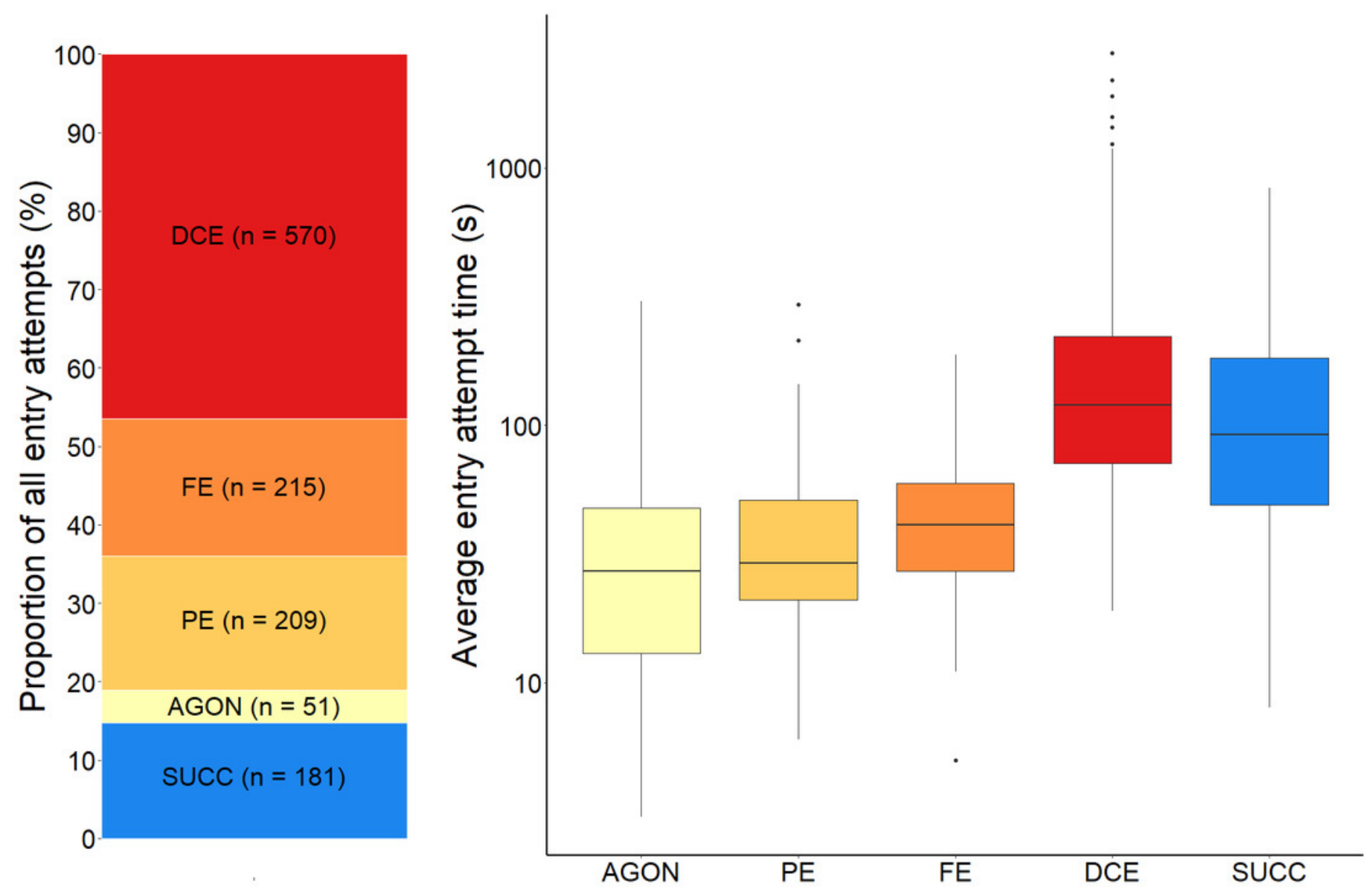


\section{Table 1 (on next page)}

Summary of green crabs caught at each study site in 2015 . 


\begin{tabular}{lllllll} 
Location & $\begin{array}{l}\text { Deployments } \\
(\mathrm{n})\end{array}$ & Mean catch & $\begin{array}{l}\text { Standard } \\
\text { deviation }\end{array}$ & $\begin{array}{l}\text { Minimum } \\
\text { catch }\end{array}$ & $\begin{array}{l}\text { Maximum } \\
\text { catch }\end{array}$ & Total catch \\
\hline Fair Haven & 16 & 131.8 & 88.2 & 10 & 299 & 2108 \\
Little Port Harmon & 12 & 34.4 & 30.4 & 0 & 102 & 413 \\
Little Harbour East & 4 & 0.5 & 1 & 0 & 2 & 2 \\
Penguin Arm & 4 & 0 & 0 & 0 & 0 & 0 \\
Bonne Bay & 20 & 0.3 & 0.6 & 0 & 2 & 5 \\
Boat Harbour & 22 & 8.6 & 34.8 & 0 & 164 & 188 \\
\hline All Sites & 78 & 34.8 & 67.5 & 0 & 299 & 2716
\end{tabular}




\section{Table 2 (on next page)}

Summary of all bycatch species caught at each study site in 2015 .

The number of green crabs caught at each site has also been included for comparison purposes. 


\begin{tabular}{|c|c|c|c|c|c|c|c|}
\hline & $\begin{array}{l}\text { Fair } \\
\text { Haven }\end{array}$ & $\begin{array}{l}\text { Little } \\
\text { Port } \\
\text { Harmon }\end{array}$ & $\begin{array}{l}\text { Boat } \\
\text { Harbour }\end{array}$ & $\begin{array}{l}\text { Little } \\
\text { Harbour } \\
\text { East }\end{array}$ & $\begin{array}{l}\text { Bonne } \\
\text { Bay }\end{array}$ & $\begin{array}{l}\text { Penguin } \\
\text { Arm }\end{array}$ & $\begin{array}{l}\text { All } \\
\text { Sites }\end{array}$ \\
\hline Rock crab (Cancer irroratus) & 0 & 2 & 116 & 0 & 84 & 4 & 206 \\
\hline Cunner (Tautogolabrus adspersus) & 0 & 0 & 8 & 0 & 39 & 7 & 54 \\
\hline Winter flounder (Pseudopleuronectes americanus) & 1 & 2 & 3 & 0 & 1 & 2 & 9 \\
\hline Sculpin sp. (Myoxocephalus sp.) & 0 & 0 & 0 & 0 & 2 & 2 & 4 \\
\hline American eel (Anguilla rostrata) & 0 & 1 & 0 & 0 & 0 & 1 & 2 \\
\hline Green crab (Carcinus maenas) & 2108 & 413 & 188 & 2 & 5 & 0 & 2716 \\
\hline
\end{tabular}




\section{Table 3 (on next page)}

Summary of data from each video that was analyzed.

Video code represents the individual deployment of a camera-equipped Fukui trap at either Fair Haven (FH), Little Port Harmon (PH), or Fox Harbour (FX). 


\begin{tabular}{|c|c|c|c|c|c|c|c|c|c|c|}
\hline $\begin{array}{l}\text { Video } \\
\text { code }\end{array}$ & $\begin{array}{l}\text { Date } \\
\text { (MM-DD- } \\
\text { YY) }\end{array}$ & $\begin{array}{l}\text { Video } \\
\text { duration } \\
\text { (h) }\end{array}$ & $\begin{array}{l}\text { \# green } \\
\text { crab } \\
\text { approaches }\end{array}$ & $\begin{array}{l}\text { \# green } \\
\text { crab } \\
\text { attempts }\end{array}$ & $\begin{array}{l}\# \\
\text { successful } \\
\text { entries by } \\
\text { green crab }\end{array}$ & $\begin{array}{l}\text { \# exits } \\
\text { by green } \\
\text { crab }\end{array}$ & $\begin{array}{l}\text { Green crab } \\
\text { success rate } \\
(\%)\end{array}$ & $\begin{array}{l}\# \\
\text { approaches } \\
\text { by other } \\
\text { species }\end{array}$ & $\begin{array}{l}\text { \# entry } \\
\text { attempts } \\
\text { by other } \\
\text { species }\end{array}$ & $\begin{array}{l}\text { \# successful } \\
\text { entries by other } \\
\text { species }\end{array}$ \\
\hline FH1 & $06 / 09 / 15$ & 7.7 & 146 & 82 & 5 & 0 & 6.1 & 46 & 15 & 1 \\
\hline $\mathrm{FH} 2$ & $06 / 09 / 15$ & 8.3 & 288 & 113 & 35 & 0 & 31.0 & 57 & 0 & 0 \\
\hline FH3 & $06 / 10 / 15$ & 6.5 & 402 & 213 & 2 & 0 & 0.9 & 83 & 6 & 0 \\
\hline FH4 & $06 / 10 / 15$ & 6.5 & 255 & 117 & 38 & 0 & 32.5 & 48 & 5 & 1 \\
\hline PH1 & $07 / 07 / 15$ & 7.9 & 453 & 191 & 13 & 0 & 6.8 & 16 & 0 & 0 \\
\hline PH5 & $07 / 09 / 15$ & 10.3 & 425 & 270 & 50 & 0 & 18.5 & 16 & 1 & 1 \\
\hline PH6 & $07 / 09 / 15$ & 13.0 & 191 & 136 & 20 & 0 & 14.7 & 81 & 2 & 0 \\
\hline FX1 & $06 / 30 / 16$ & 13.0 & 213 & 104 & 18 & 0 & 17.3 & 4 & 1 & 0 \\
\hline
\end{tabular}

